Key Words:

DWPF

Acid usage

Retention:

Permanent

\title{
INITIAL CHARACTERIZATIONS AND SRAT SIMULATIONS OF FOUR SLUDGE MATRIX STUDY SIMULANTS
}

\author{
D. C. Koopman \\ D. P. Lambert
}

DECEMBER 2009

Savannah River National Laboratory

Savannah River Nuclear Solutions

Aiken. SC 29808

Prepared for the U.S. Department of Energy Under Contract Number DE-AC09-08SR22470 


\section{DISCLAIMER}

This work was prepared under an agreement with and funded by the U.S. Government. Neither the U. S. Government or its employees, nor any of its contractors, subcontractors or their employees, makes any express or implied:

1. warranty or assumes any legal liability for the accuracy, completeness, or for the use or results of such use of any information, product, or process disclosed; or

2. representation that such use or results of such use would not infringe privately owned rights; or

3. endorsement or recommendation of any specifically identified commercial product, process, or service.

Any views and opinions of authors expressed in this work do not necessarily state or reflect those of the United States Government, or its contractors, or subcontractors.

Printed in the United States of America

Prepared for

U.S. Department of Energy 
Key Words:

DWPF

Acid usage

Retention:

Permanent

\title{
INITIAL CHARACTERIZATIONS AND SRAT SIMULATIONS OF FOUR SLUDGE MATRIX STUDY SIMULANTS
}

\author{
D. C. Koopman \\ D. P. Lambert
}

DECEMBER 2009

Savannah River National Laboratory

Savannah River Nuclear Solutions

Savannah River Site

Aiken, SC 29808 


\section{REVIEWS AND APPROVALS}

D. C. Koopman, Process Technology Programs

Date

D. P. Lambert, Process Technology Programs

Date

M. E. Stone, Peer Reviewer, Process Technology Programs

Date

C. C. Herman, Manager, Process Technology Programs

Date

S. L. Marra, Manager,

Date

Environmental \& Chemical Process Technology Research Programs

J. E. Occhipinti, Manager

Date

Waste Solidification Engineering

- ii - 


\section{TABLE OF CONTENTS}

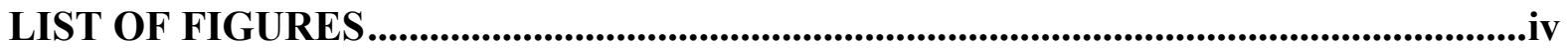

LIST OF TABLES.....................................................................................................................

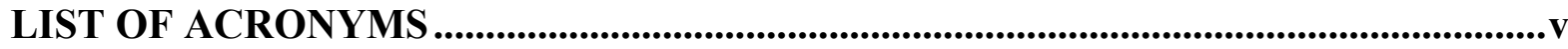

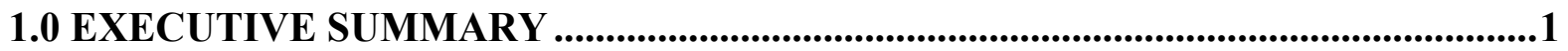

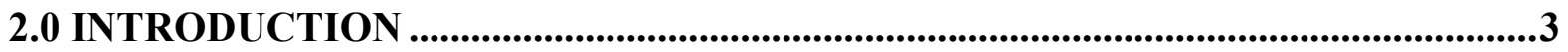

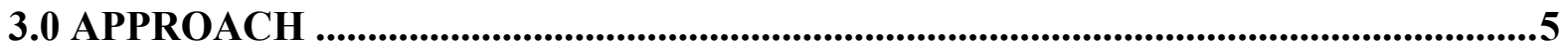

3.1 Process and Sample Analytical Methods ...............................................................................5

3.2 Simulant Preparation and Characterization .....................................................................6

3.3 Chemical Process Cell Simulation Details .......................................................................8

4.0 SRAT SIMULATION RESULTS .........................................................................11

4.1 Anion Composition Changes .........................................................................................11

4.2 Elemental and Dissolution Data......................................................................................13

4.3 Mercury ..............................................................................................................................15

4.4 Ammonium Production .......................................................................................................17

4.5 Probe Data ......................................................................................................................................17

4.6 Rheological Data...................................................................................................................21

4.7 Off-gas Data ................................................................................................................................23

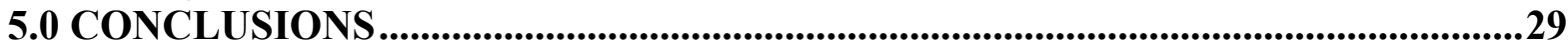

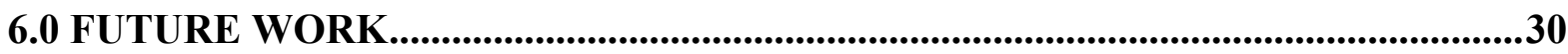

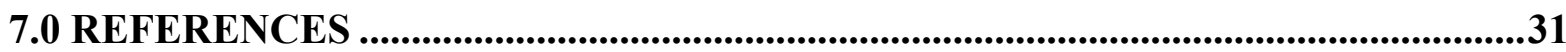

APPENDIX A. RHEOLOGY DATA......................................................................................32 


\section{LIST OF FIGURES}

Figure 1. Hi Mn run $\mathrm{pH}$ probe data 18

Figure 2. ORP and pH probe data for the Hi Fe-Lo Mn run ............................................ 19

Figure 3. ORP and $\mathrm{pH}$ probe data for the Lo Fe-Lo Mn run ...........................................20

Figure 4. Comparison of Hi Fe and Lo Fe ORP data at Lo Mn ........................................21

Figure 5. Flow curve data for the Hi Fe-Lo Mn SRAT product.........................................22

Figure 6. Composite carbon dioxide GC data converted to DWPF scale flow .....................24

Figure 7. Composite nitrous oxide GC data converted to DWPF scale flow ........................25

Figure 8. Composite of the derived $\mathrm{NO}_{2}\left(\mathrm{~N}_{2} \mathrm{O}_{4}\right)$ generation rates .....................................26

Figure 9. Performance of Nafion dryer during Lo Fe-Lo Mn test.......................................28

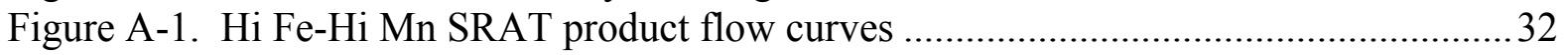

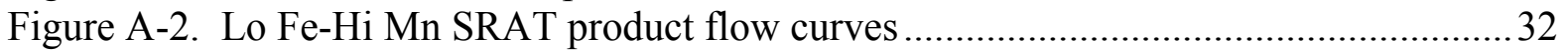

Figure A-3. Lo Fe-Lo Mn SRAT product flow curves.................................................... 33

\section{LIST OF TABLES}

Table 1. Elemental composition of simulants calcined at $1100^{\circ} \mathrm{C}$, wt $\%$.............................. 7

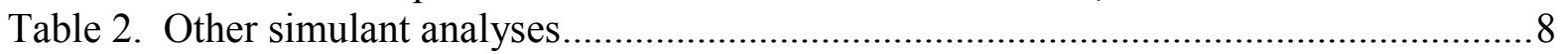

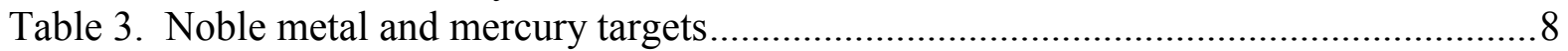

Table 4. Stoichiometric acid calculation results, moles acid/L slurry ................................9

Table 5. Anion concentration, $\mathrm{mg} / \mathrm{kg}$ slurry, after acid addition.......................................... 11

Table 6. Anion concentration, $\mathrm{mg} / \mathrm{kg}$, end of SRAT cycle ............................................... 12

Table 7. Anion reaction extents in SRAT cycle, \% .......................................................... 13

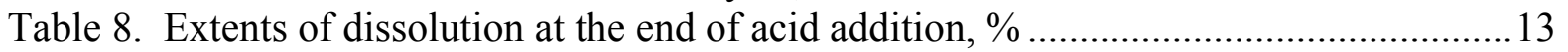

Table 9. Extents of dissolution at the end of SRAT cycle, $\%$........................................... 15

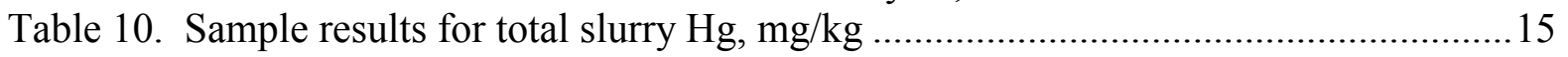

Table 11. Sample results for ammonium in the chilled condensate, $\mathrm{mg} / \mathrm{L}$..........................17

Table 12. SRAT product Bingham plastic model results ..............................................22 


\section{LIST OF ACRONYMS}

$\begin{array}{ll}\text { ACTL } & \text { Aiken County Technology Laboratory } \\ \text { AD } & \text { Analytical Development } \\ \text { CPC } & \text { Chemical Process Cell } \\ \text { DWPF } & \text { Defense Waste Processing Facility } \\ \text { E\&CPT } & \text { Environmental and Chemical Process Technology } \\ \text { FAVC } & \text { Formic Acid Vent Condenser } \\ \text { GC } & \text { Gas Chromatograph } \\ \text { IC } & \text { Ion Chromatography } \\ \text { ICP-AES } & \text { Inductively Coupled Plasma-Atomic Emission Spectroscopy } \\ \text { ICP-MS } & \text { Inductively Coupled Plasma-Mass Spectroscopy } \\ \text { LWO } & \text { Liquid Waste Organization } \\ \text { MWWT } & \text { Mercury Water Wash Tank } \\ \text { PSAL } & \text { Process Science Analytical Laboratory } \\ \text { QA } & \text { Quality Assurance } \\ \text { SB } & \text { Sludge Batch } \\ \text { SCFM } & \text { Standard Cubic Feet per Minute } \\ \text { SLM } & \text { Standard Liters per Minute } \\ \text { SME } & \text { Slurry Mix Evaporator } \\ \text { SRAT } & \text { Sludge Receipt and Adjustment Tank } \\ \text { SRNL } & \text { Savannah River National Laboratory } \\ \text { TA } & \text { Technical Analyst } \\ \text { TIC } & \text { Total Inorganic Carbon } \\ \text { TR } & \text { Technical Report } \\ & \end{array}$




\subsection{EXECUTIVE SUMMARY}

The Savannah River National Laboratory (SRNL) initiated a sludge matrix study to evaluate the impact of changing insoluble solid composition on the processing characteristics of slurries in the Defense Waste Processing Facility (DWPF). Three compositional ranges were developed for three groups of elements in the waste. The first was high iron/low aluminum versus low iron/high aluminum. The second was high calcium-manganese/low nickel, chromium, and magnesium versus low calcium-manganese/high nickel, chromium, and magnesium. The third was high noble metals ( $\mathrm{Ag}, \mathrm{Pd}, \mathrm{Rh}, \mathrm{Ru})$ versus low noble metals. These three options can be combined to form eight distinct sludge compositions.

The sludge matrix study called for testing each of these eight simulants near the minimum acid required for nitrite destruction and at a second acid level that produced significant hydrogen by noble metal catalyzed decomposition of formic acid. Four simulants were prepared based on the four possible combinations of the $\mathrm{Al} / \mathrm{Fe}$ and $\mathrm{Mn}-\mathrm{Ca} / \mathrm{Mg}-\mathrm{Ni}-\mathrm{Cr}$ options. Preliminary simulant preparation work has already been documented. ${ }^{3}$ The four simulants can be used for both high and low noble metal concentration testing and high and low acid testing. This report summarizes preliminary testing of each of the four simulants at low noble metals and low acid stoichiometry. The remaining matrix study tests are on hold.

Chemically processed simulant was needed for U. S. Department of Energy-Office of Environmental Management and DWPF funded melt rate studies. Therefore, a preliminary assessment of the processing characteristics of the four sludge matrix simulants was completed using the low noble metal concentration option to meet this need. Sludge Receipt and Adjustment Tank (SRAT) testing was at low total acid stoichiometry (near the minimum acid end of the stoichiometric acid window). Composition and physical property measurements were made on the SRAT products. Updated values for formate loss and nitrite-to-nitrate conversion were found that can be used in the acid calculations for future sludge matrix process simulations.

A reasonable determination of the minimum acid requirement for nitrite destruction was found to be slightly less than $105 \%$ of the Koopman minimum stoichiometric acid equation prediction for all four simulants at the low noble metal concentrations. The Koopman minimum stoichiometric acid equation is based on supernate carbonate, plus total $\mathrm{Mg}$ and $\mathrm{Ca}$, in addition to the usual DWPF inputs such as base equivalents and $\mathrm{Mn}^{4}$ This group of four tests extends the range of bulk insoluble solids concentrations over which the new Koopman minimum stoichiometric acid equation has been validated. The low iron-low manganese case appeared to have somewhat more excess acid than the other three combinations.

Preliminary results of the initial testing indicate:

- Hydrogen generation rate was not an issue in these tests.

- Mercury stripping was less efficient than expected at about $1000 \mathrm{~g}$ steam $/ \mathrm{g}$ mercury stripped. Only about $25 \%$ of the initial concentration of $1.5 \mathrm{wt} \% \mathrm{Hg}$ in the total solids was removed in 13-14 hours of boiling, when $70 \%$ needed to be removed to meet the DWPF SRAT product specification of $0.45 \mathrm{wt} \%$ in the total solids. 
- Foaminess was not an issue using the nominal antifoam addition strategy in these tests.

- Ammonia generation was not an issue based on off-gas condensate analyses.

- One of the SRAT products (an HM-type simulant) was much more viscous than the other three SRAT products even though it had the lowest $\mathrm{wt} \%$ insoluble solids.

More comprehensive results concerning the impact of insoluble solids composition on processing, melt rate, etc. must await completion of the full sludge matrix study experimental scope. 


\subsection{INTRODUCTION}

SRNL recommended a sludge matrix study to DWPF in order to improve the understanding of how changing sludge composition impacts DWPF waste processing. Specifically, the study was to focus on how changes in the composition of the insoluble species impact processing. Supernate compositions were to be maintained nearly constant in the proposed study, that is, the proposed study was not an evaluation of the impact of different washing strategies on DWPF processing. The study was included in the task to improve the DWPF stoichiometric acid equation for the SRAT. ${ }^{1}$

There are many elements in the insoluble solids. The two major insoluble elements in SRS high activity waste slurries are iron and aluminum, corresponding to Purex and HM wastes respectively. The first solids concentration parameter was chosen to reflect variations between these two elements. There are a number of elements that occur at about an order of magnitude lower concentration than $\mathrm{Al}$ and $\mathrm{Fe}$ in SRS waste slurries including $\mathrm{Ca}, \mathrm{Hg}, \mathrm{Mg}$, $\mathrm{Mn}, \mathrm{Ni}$, and $\mathrm{Si}$ (also $\mathrm{U}$, but that is outside the scope of this study). These can be defined as the semi-major elements. Creating high-low pairs from all of these elements in addition to $\mathrm{Al}$ and Fe would have led to a prohibitively large study.

The size of the study was controlled by grouping some of the semi-major elements into two sets. Manganese was paired with $\mathrm{Ca}$, and $\mathrm{Mg}$ was paired with $\mathrm{Ni}$. This defined the second concentration parameter in the study. Silicon, as $\mathrm{SiO}_{2}$, was seen as essentially inert and not included in the pairings with the other semi-major elements. Mercury has been studied in other contexts. Therefore, mercury will be held at $1.5 \mathrm{wt} \%$ in the starting sludge total solids in all proposed tests in the sludge matrix study. $\mathrm{Cr}$ is typically at least an order of magnitude lower in concentration than the semi-major elements. It was considered potentially significant, however, due to its several oxidation states and was added to the $\mathrm{Mg}-\mathrm{Ni}$ pair. Another constraint on handling the semi-major elements was that the sum of oxides must sum to $100 \%$. Suppressing or enhancing the concentrations of all of the semi-major elements simultaneously would have led to unreasonably high or low concentrations of either $\mathrm{Al}$ or Fe. Conceptually, the second concentration parameter represents reasonable compositional variations within each of the two main waste types, Purex or HM.

Noble metals ( $\mathrm{Ag}, \mathrm{Pd}, \mathrm{Rh}$, and $\mathrm{Ru}$ ) have been recognized as being highly significant to waste processing in spite of their low concentrations. ${ }^{2}$ Rhodium and ruthenium have been found to have the most impact on catalytic hydrogen generation. They typically are found in SRS waste at close to the fission yield ratio of about $3.75 \mathrm{Ru} / \mathrm{Rh}$. Noble metals were chosen to form the third concentration parameter in the matrix study. The three primary parameter groups drawn from the insoluble solids are summarized below:

- High iron or high aluminum (representing Purex and HM wastes respectively). This parameter is referred to as either Hi Fe or Lo Fe in the discussion below.

- High Mn and $\mathrm{Ca}$ or high $\mathrm{Mg}, \mathrm{Ni}$, and $\mathrm{Cr}$ (representing the semi-major insoluble species). This parameter is referred to as either Hi Mn or Lo Mn below. 
- High noble metals or low noble metals ( $\mathrm{Ag}, \mathrm{Pd}, \mathrm{Rh}$ and $\mathrm{Ru}$ are recognized as having a collectively major impact on SRAT chemistry)

The other (minor) sludge species, such as $\mathrm{Ba}, \mathrm{Zn}, \mathrm{Zr}, \mathrm{Cu}$, $\mathrm{La}$, etc., were to be held in constant relative proportions in the simulants.

Eight high-low combinations of the three insoluble solids concentration parameters can be formed, for example high Fe-high Mn-high noble metals. The sludge matrix study also includes a fourth parameter, total acid. It was desired to evaluate the impact of a fixed change in total acid on the processing characteristics of the eight different insoluble solids combinations. The four parameters required a full factorial experimental design with sixteen SRAT simulations. To test for non-linearity and to evaluate reproducibility, or variance, a midpoint SRAT simulation was added along with a replicate trial. The midpoint simulant can be made by blending the four different untrimmed simulants that are required and then trimming the blend to the midpoint noble metal concentrations.

Four different primary simulants were required as a starting point for the sludge matrix program. These can be described as Hi Fe-Hi Mn, Hi Fe-Lo Mn, Lo Fe-Hi Mn, and Lo FeLo Mn. Each simulant would be used four times to obtain data at high and low noble metal concentrations with both high and low acid additions. In addition, some of each of the four simulants is needed to prepare the midpoint composition simulant. Preliminary results of the simulant preparation process have been summarized. ${ }^{3}$ Some of the data presented below come from analyses performed after the simulant preparation summary memo was issued.

It was anticipated when this program started in 2005 that some scoping runs might be needed to find the approximate acid stoichiometry that would give the minimum acid needed to destroy nitrite ion to less than $1,000 \mathrm{mg} / \mathrm{kg}$ in the SRAT product. The scoping runs could require simulant in addition to that used in completing the statistical matrix portion of the study. A new equation for estimating the stoichiometric acid requirement was developed during the intervening period, however. The Koopman minimum acid equation (see Section 3.3 for a description of the equation) was selected to determine the acid requirement of each simulant. $^{4}$ 


\subsection{APPROACH}

\subsection{PROCESS AND SAMPLE ANALYTICAL METHODS}

The automated data acquisition system developed for the 4-L SRAT rigs was used to collect electronic data on a computer. Collected data included SRAT temperature, bath temperatures for the cooling water to the SRAT condenser and Formic Acid Vent Condenser (FAVC), slurry $\mathrm{pH}$, SRAT mixer speed and torque, air and helium purge flows (He is used as an internal standard and is set to $0.5 \%$ of the nominal SRAT air purge flow). Cumulative acid addition volume data were collected from the automated dispensers using an algorithm that matches the indicated total on the dispenser. All of the tests had a $\mathrm{pH}$ probe in the SRAT slurry to monitor $\mathrm{pH}$. Raw GC data were generally acquired on separate computers dedicated to each instrument.

Agilent 3000A micro GC's were used on all four runs. The GC's were baked out before and between runs. Column-A can collect data related to $\mathrm{He}, \mathrm{H}_{2}, \mathrm{O}_{2}, \mathrm{~N}_{2}, \mathrm{NO}$, and $\mathrm{CO}$, while column-B can collect data related to $\mathrm{CO}_{2}$ and $\mathrm{N}_{2} \mathrm{O}$. GC's were calibrated with a standard calibration gas containing $0.499 \mathrm{vol} \% \mathrm{He}, 1.000 \mathrm{vol} \% \mathrm{H}_{2}, 20.00 \mathrm{vol} \% \mathrm{O}_{2}, 51.0 \mathrm{vol} \% \mathrm{~N}_{2}$, $25.0 \mathrm{vol} \% \mathrm{CO}_{2}$ and $2.50 \mathrm{vol} \% \mathrm{~N}_{2} \mathrm{O}$. The calibration was verified prior to starting the SRAT cycle. Room air was used to give a two point calibration for $\mathrm{N}_{2}$. The GC's were rechecked with calibration gas following the SRAT cycle. No evidence for CO generation was obtained while examining the region of the chromatogram where it would elute.

The chilled off-gas leaving the FAVC was passed through a Nafion dryer in counter-current flow with a dried air stream to reduce the moisture content at the GC inlet. A fairly small unit was selected to minimize pressure drop, but it appears to be possible to significantly reduce the moisture content in the stream being sampled by the GC. The inlet GC samples also passed through small sintered metal filters prior to injection into the two columns.

Process samples were analyzed by various methods. Slurry and supernate elemental compositions were determined by inductively coupled plasma-atomic emission spectroscopy (ICP-AES) at the Process Science Analytical Laboratory (PSAL). Slurry samples were calcined at $1100^{\circ} \mathrm{C}$, however, so noble metals, $\mathrm{Pb}$, and $\mathrm{Cr}$ were likely underreported due to the potential for volatility. The main advantage of this approach is to permit easier comparisons between SRAT product elements and sludge elements. Analytical data on $\mathrm{Pb}$ and $\mathrm{Cr}$ slurry concentrations are not critical to understanding processing, since their relative abundances in the simulant are known from the preparation recipes. Noble metals are trimmed uniquely to each SRAT, and their concentrations are known more accurately from material balance considerations than they could be from ICP-AES analyses.

Soluble slurry anions were determined by ion chromatography (IC) on 100-fold weighted dilutions of slurry with water after filtering out insoluble solids. SRAT product slurry samples were submitted to Analytical Development (AD) for mercury analysis. Starting sludges were submitted to AD for total inorganic carbon analysis of both the total slurry and the supernate. Starting sludges were analyzed for slurry and supernate density using the 
Anton-Parr instrument at ACTL. Starting sludges were titrated to $\mathrm{pH} 7$ using the ACTL auto-titrator to determine the base equivalents for input into the stoichiometric acid equation. Condensates from the FAVC were analyzed by cation chromatography for ammonium ion.

\subsection{SIMULANT PREPARATION AND CHARACTERIZATION}

Four distinct simulants were prepared using the current continuous stirred tank precipitator (CSTR) method. This method involved the following processing steps:

- A slurry of precipitated $\mathrm{MnO}_{2}$ was prepared.

- An acidic metal nitrate solution was prepared.

- The two were combined and fed to the CSTR along with a $50 \mathrm{wt} \%$ sodium hydroxide solution to produce a basic slurry of hydrous metal oxide and hydroxide solids in a sodium nitrate solution at a $\mathrm{pH}$ of about 9.5 .

- The slurry was contacted with sodium carbonate to permit conversion of some of the hydroxides to carbonates.

- The slurry was decanted and washed until the nitrate concentration was below the target supernate nitrate concentration.

- The slurry was concentrated to a point consistent with the targeted total solids value for the final slurry.

- Silica, $\mathrm{TiO}_{2}$, and sodium salts were added to complete the preparation.

As discussed in Section 2.0, the four matrix study simulants targeted identical supernate compositions with the compositional variations in the insoluble solids. Two of the simulants were high in iron and low in aluminum, while two were low in iron and high in aluminum. One of each pair was high in manganese and calcium while the other was low in manganese and calcium. Simulants that were low in manganese and calcium had more magnesium, nickel, and chromium. Following completion of the simulant preparation, the low iron-high manganese simulant was not as comparable to the other three as desired. The portion of that simulant used in the initial testing was decanted to increase total solids content and trimmed with additional sodium hydroxide to increase the titrated base equivalents. Table 1 presents the average elemental results of duplicate analyses of two slurry samples from each simulant calcined at $1100^{\circ} \mathrm{C}$. 
Table 1. Elemental composition of simulants calcined at $1100^{\circ} \mathrm{C}$, wt $\%$

\begin{tabular}{|c|c|c|c|c|}
\hline Element & Hi Fe-Hi Mn & Hi Fe-Lo Mn & Lo Fe-Hi Mn & Lo Fe-Lo Mn \\
\hline $\mathrm{Al}$ & 9.18 & 9.32 & 23.4 & 24.1 \\
\hline $\mathrm{Ba}^{*}$ & 0.081 & 0.102 & 0.051 & 0.067 \\
\hline $\mathrm{Ca}$ & 3.86 & 2.08 & 3.38 & 1.86 \\
\hline $\mathrm{Ce}{ }^{*}$ & 0.104 & 0.106 & 0.115 & 0.095 \\
\hline $\mathrm{Cr}$ & 0.020 & 0.290 & 0.015 & 0.255 \\
\hline $\mathrm{Cu}^{*}$ & 0.054 & 0.053 & 0.052 & 0.048 \\
\hline $\mathrm{Fe}$ & 32.4 & 32.1 & 11.3 & 12.6 \\
\hline $\mathrm{K}^{*}$ & 0.110 & 0.076 & 0.134 & 0.097 \\
\hline $\mathrm{La}{ }^{*}$ & 0.050 & 0.049 & 0.017 & 0.045 \\
\hline $\mathrm{Mg}^{*}$ & 0.412 & 2.81 & 0.311 & 2.55 \\
\hline $\mathrm{Mn}^{*}$ & 4.06 & 0.694 & 3.59 & 0.671 \\
\hline $\mathrm{Na}^{*}$ & 13.2 & 13.8 & 16.6 & 14.8 \\
\hline $\mathrm{Ni}^{*}$ & 0.210 & 2.61 & 0.204 & 2.27 \\
\hline $\mathrm{P}^{*}$ & 0.014 & 0.014 & 0.016 & 0.016 \\
\hline $\mathrm{Pb}^{*}$ & 0.084 & 0.049 & 0.089 & 0.070 \\
\hline $\mathrm{S}^{*}$ & 0.290 & 0.295 & 0.356 & 0.352 \\
\hline $\mathrm{Si}^{*}$ & 1.56 & 1.55 & 1.42 & 1.37 \\
\hline $\mathrm{Sn}^{*}$ & 0.033 & 0.030 & 0.026 & 0.032 \\
\hline $\mathrm{Ti}^{*}$ & 0.026 & 0.026 & 0.023 & 0.025 \\
\hline $\mathrm{Zn}^{*}$ & 0.059 & 0.042 & 0.043 & 0.058 \\
\hline $\mathrm{Zr}^{*}$ & 0.058 & 0.122 & 0.050 & 0.052 \\
\hline
\end{tabular}

* - elements not being deliberately varied as part of the study

The species being deliberately varied included $\mathrm{Al}, \mathrm{Ca}, \mathrm{Cr}, \mathrm{Fe}, \mathrm{Mg}, \mathrm{Mn}$, and $\mathrm{Ni}$. The targeted variations were very apparent in the analytical results indicating that the four simulants were suitable for subsequent testing from an elemental standpoint. The other elements were not deliberately varied, although some small variations occurred as a consequence of the variations in the targeted elements.

Table 2 presents results for total, insoluble, soluble and calcined wt $\%$ solids, slurry and supernate density, slurry base equivalent molarity, slurry and supernate total inorganic carbon (TIC), and the slurry anion results from IC. The Lo Fe-Hi Mn simulant was adjusted from its original composition, reported at $21.5 \mathrm{wt} \%$ total solids, by decanting and trimming in supernate species to raise the $\mathrm{wt} \%$ total solids. Various pieces of data obtained subsequently indicate that the pre-adjustment total solids may have been closer to $21 \mathrm{wt} \%$. The adjusted Lo Fe-Hi Mn simulant was analyzed to be $21.7 \mathrm{wt} \%$ total solids, when it should have been close to $22.8 \%$ if it actually had been at about $21.5 \mathrm{wt} \%$ prior to trimming. The adjustment protocol for the Lo Fe-Hi Mn simulant will be modified before performing additional SRAT tests in order to increase the total solids content further. 
Table 2. Other simulant analyses

\begin{tabular}{|l|c|c|c|c|}
\hline & $\begin{array}{c}\text { Hi Fe- } \\
\text { Hi Mn }\end{array}$ & $\begin{array}{c}\text { Hi Fe- } \\
\text { Lo Mn }\end{array}$ & $\begin{array}{c}\text { Lo Fe- } \\
\text { Hi Mn }\end{array}$ & $\begin{array}{c}\text { Lo Fe- } \\
\text { Lo Mn }\end{array}$ \\
\hline Total solids, wt\% & 23.6 & 22.8 & 21.7 & 23.1 \\
\hline Insoluble solids, wt\% & 17.1 & 16.4 & 14.3 & 16.2 \\
\hline Soluble solids, wt\% & 6.6 & 6.5 & 7.4 & 6.9 \\
\hline Calcined solids, wt\% & 17.6 & 16.8 & 14.7 & 15.7 \\
\hline Slurry density, g/mL & 1.195 & 1.180 & 1.168 & 1.172 \\
\hline Supernate density, g/mL & 1.057 & 1.055 & 1.057 & 1.059 \\
\hline Slurry base equiv., mol/kg & 0.462 & 0.457 & 0.470 & 0.428 \\
\hline & & & & \\
\hline Nitrite, $\mathrm{mg} / \mathrm{kg}$ & 17,700 & 17,200 & 17,000 & 17,800 \\
\hline Nitrate, $\mathrm{mg} / \mathrm{kg}$ & 14,000 & 13,600 & 13,200 & 13,800 \\
\hline Sulfate, $\mathrm{mg} / \mathrm{kg}$ & 1,690 & 1,480 & 1,480 & 1,520 \\
\hline Oxalate, $\mathrm{mg} / \mathrm{kg}$ & 310 & 300 & 300 & 310 \\
\hline Chloride, $\mathrm{mg} / \mathrm{kg}$ & 120 & 130 & 130 & 130 \\
\hline Slurry TIC, $\mathrm{mg} / \mathrm{kg}$ & 2,750 & 2,490 & 2,400 & 2,410 \\
\hline Supernate TIC, $\mathrm{mg} / \mathrm{kg}$ & 1,080 & 1,310 & 1,280 & 1,240 \\
\hline
\end{tabular}

The key input parameters for the stoichiometric acid equation calculations in Table 2, such as nitrite, TIC, and base equivalents, typically fell within $10 \%$ of the average value for a given row indicating that essentially equivalent supernates were prepared for the four simulants.

All tests had 2,900 $\mathrm{g}$ of starting sludge (before trim chemicals and rinse water). Rh was trimmed as a solution of $\mathrm{Rh}\left(\mathrm{NO}_{3}\right)_{3}$ containing $4.93 \mathrm{wt} \%$ rhodium. Ru was added as the dry trivalent chloride salt at a purity of $41.73 \mathrm{wt} \% \mathrm{Ru}$. Pd was trimmed as a solution of $\mathrm{Pd}\left(\mathrm{NO}_{3}\right)_{2}$ containing $15.27 \mathrm{wt} \%$ palladium. Silver was added as the dry nitrate salt $\mathrm{AgNO}_{3}$. Mercury was trimmed as dry $\mathrm{HgO}$. The first four sludge matrix simulations had identical mercury and noble metal targets, given in Table 3 as $\mathrm{wt}^{\mathrm{O}} \%$ in the total solids of the trimmed slurry.

Table 3. Noble metal and mercury targets

\begin{tabular}{|c|c|c|c|c|c|}
\hline & Ag & Pd & Rh & Ru & Hg \\
\hline wt $\%$ in total solids & 0.0010 & 0.0003 & 0.0026 & 0.0101 & 1.500 \\
\hline
\end{tabular}

The above noble metals concentrations are comparable to the low noble metal case in the recent $\mathrm{Rh}-\mathrm{Ru}-\mathrm{Hg}$ matrix study, while mercury was held constant during the sludge simulant matrix study at the midpoint value of the $\mathrm{Rh}-\mathrm{Ru}-\mathrm{Hg}$ matrix study. ${ }^{2}$ The levels were selected to permit some simpler comparisons between results from the two studies.

\subsection{CHEMICAL PROCESS CELL SIMULATION DETAILS}

The trimmed SRAT receipt volume was about $2.5 \mathrm{~L}$. The 4-L lab-scale SRAT equipment was used for these tests. One stoichiometric factor was used in all four acid calculations, 
$105 \%$. This factor was chosen to potentially ensure nitrite destruction to below $1,000 \mathrm{mg} / \mathrm{kg}$ SRAT product slurry while keeping hydrogen generation to a minimum. Acid calculations were based on the new Koopman minimum acid requirement equation: ${ }^{4}$

$$
\frac{\text { moles acid }}{L \text { slurry }}=\text { base equivalents }+H g+\text { soluble } T I C+1.5 *(C a+M g)+1.0 * \text { nitrite }+1.5 * M n
$$

Acid calculations were also performed using the current DWPF algorithm for comparison: ${ }^{5}$

$$
\frac{\text { moles acid }}{\text { L slurry }}=\text { base equivalents }+2 * \text { total } \mathrm{TIC}+0.75 * \text { nitrite }+1.2 * \mathrm{Mn}+\mathrm{Hg}
$$

The results of these two calculations for the four simulants are summarized in Table 4 . The table also includes the actual acid additions made based on $105 \%$ of the Koopman minimum acid equation and the equivalent DWPF stoichiometric factors (percent) to go from the DWPF acid equation values to the actual acid additions.

Table 4. Stoichiometric acid calculation results, moles acid/L slurry

\begin{tabular}{|l|c|c|c|c|}
\hline & $\begin{array}{c}\text { DWPF Eqn. } \\
\text { moles/L }\end{array}$ & $\begin{array}{c}\text { Koopman Min. } \\
\text { moles/L }\end{array}$ & $\begin{array}{c}\text { Actual addition at } \\
105 \%, \text { moles/L }\end{array}$ & $\begin{array}{c}\text { Equivalent } \\
\text { DWPF factor }\end{array}$ \\
\hline Hi Fe-Hi Mn & 1.652 & 1.711 & 1.797 & $109 \%$ \\
\hline Hi Fe-Lo Mn & 1.409 & 1.659 & 1.742 & $124 \%$ \\
\hline Lo Fe-Hi Mn & 1.505 & 1.549 & 1.626 & $108 \%$ \\
\hline Lo Fe-Lo Mn & 1.357 & 1.529 & 1.606 & $113 \%$ \\
\hline
\end{tabular}

The Koopman minimum stoichiometric acid equation results were 3-18\% higher than the DWPF equation results. The range of Koopman minimum equation results fell within $\pm 6 \%$ of the average value of 1.612 moles acid/L slurry. Variations in calculated acid demand due to changing $\mathrm{Mn}$ and $\mathrm{Ca}$ concentration were partially offset by changes in the $\mathrm{Mg}$ concentration. This effect was responsible for the narrow range in Koopman minimum equation acid requirements for four very different insoluble sludge species compositions.

The equivalent stoichiometric factors using the current DWPF equation varied between 108124\%. The Hi Fe-Hi Mn simulant is generally similar to the first few DWPF sludge batch compositions except for having a less washed supernate. Nitrite destruction required 125$130 \%$ stoichiometries with the DWPF acid equation. The less washed Hi Fe-Lo Mn supernate has a higher fraction of acid demand that is well counted by the DWPF acid equation (base equivalents, soluble carbonate, and nitrite) which qualitatively explains the lower overall correction factor of $109 \%$.

Total acid was partitioned between formic and nitric acids using the latest RedOx equation. ${ }^{6}$ Assumptions of $15 \%$ formate loss and $30 \%$ nitrite-to-nitrate conversion were also made to enable this calculation to be performed without any prior experience with these simulants. 
These are reasonable assumptions for low noble metal-low acid simulations. This gave the fraction of total acid that was formic acid in the range of 0.901-0.956.

Scaled design basis DWPF SRAT/SME processing conditions were generally used. The SRAT cycle, however, did not have a heel from a prior batch.

- $\quad$ The SRAT air purge scaled to $230 \mathrm{scfm}$ in DWPF.

- A 200 ppm antifoam addition was made prior to nitric acid addition.

- A 100 ppm antifoam addition was made prior to formic acid addition.

- Nitric and formic acid addition were made at $93^{\circ} \mathrm{C}$.

- Acids were added at two gallons per minute scaled from 6,000 gallons to $2.5 \mathrm{~L}$.

- A $500 \mathrm{ppm}$ antifoam addition was made prior to going to boiling following acid addition.

- Boiling assumed a condensate production rate of 5,000 lbs/hr at DWPF scale.

- SRAT dewatering took about 80-90 minutes to produce a $26 \mathrm{wt} \%$ total solids slurry.

- Reflux followed dewatering. The end of the 12-hour reflux period defined the end of the SRAT cycle.

Several samples were taken during the SRAT cycle to monitor major reactions. It was projected that mercury might exceed the DWPF SRAT product limit after only 13-14 total hours at boiling due to the high starting concentration. The SRAT product slurry was sampled directly into a digestion bottle while mixing once it had cooled to $90^{\circ} \mathrm{C}$. These samples were for mercury analysis. Additional SRAT product samples were taken after the product had cooled and been weighed for compositional and solids analyses. The MWWT and FAVC were drained and weighed. The FAVC condensate was submitted for ammonium ion analysis.

A complete SRAT simulation took about 21 hours measured from the start of heating prior to acid addition in the SRAT until the time that the SRAT product had cooled to less than $50^{\circ} \mathrm{C}$. 


\subsection{SRAT SIMULATION RESULTS}

\subsection{ANION COMPOSITION CHANGES}

Samples were taken in each of the four SRAT simulations to monitor reactions of the major anions. Anions were determined by IC. The first sample was taken at the end of acid addition in each run. These four samples were quenched with $1 \mathrm{M} \mathrm{NaOH}$ to stop reactions with acids. Matching samples were taken, centrifuged, and analyzed for dissolved elements. The main purpose of these two groups of samples was to evaluate the extent of destruction of nitrite versus the extent of manganese reduction at a fixed point in the process.

Initial nitrite concentrations were about $17,500 \mathrm{mg} / \mathrm{kg}$ slurry. Rinse water and acid dilution would have decreased the initial nitrite concentration to about 16,100 by the end of acid addition in the absence of chemical reactions. Results from the caustic-quenched samples are given in Table 5 after correcting to remove the effect of the caustic dilution.

Table 5. Anion concentration, $\mathrm{mg} / \mathrm{kg}$ slurry, after acid addition

\begin{tabular}{|l|c|c|c|c|}
\hline & $\begin{array}{c}\text { Hi Fe- } \\
\text { Hi Mn }\end{array}$ & $\begin{array}{c}\text { Hi Fe- } \\
\text { Lo Mn }\end{array}$ & $\begin{array}{c}\text { Lo Fe- } \\
\text { Hi Mn }\end{array}$ & $\begin{array}{c}\text { Lo Fe- } \\
\text { Lo Mn }\end{array}$ \\
\hline Nitrite ion & 8,700 & 7,100 & 8,200 & 6,100 \\
\hline Formate ion & 50,300 & 45,200 & 49,100 & 44,500 \\
\hline Nitrate ion & 22,000 & 28,000 & 23,000 & 25,000 \\
\hline Sulfate ion & 180 & $<100$ & 550 & 130 \\
\hline Formic/Total acid & 0.9564 & 0.9012 & 0.9522 & 0.9161 \\
\hline SRAT pH & 4.5 & 4.2 & $4.5^{\S}$ & 4.3 \\
\hline
\end{tabular}

$$
\S \text { - second } \mathrm{pH} \text { probe for this run }
$$

Nitrite ion was $46-62 \%$ destroyed by the end of acid addition based on the analytical results. Feed nitrate plus nitric acid nitrate would give nitrate concentrations in the 16,000-19,000 $\mathrm{mg} / \mathrm{kg}$ range following acid addition, so the above data also indicate that nitrite-to-nitrate conversion was underway, which is consistent with the nitrite destruction data. Formate tracked with the fraction of the total acid that was formic acid. The two high Mn runs had higher formic acid fractions and higher end of acid addition formate concentrations as expected.

Anion data for the Lo Fe-Hi Mn case also showed $\sim 1,000 \mathrm{mg} / \mathrm{kg}$ chloride compared to 120$130 \mathrm{mg} / \mathrm{kg}$ in the Lo Fe-Hi Mn starting sludge and in the three other runs. The $\mathrm{pH}$ probe broke during formic acid addition in this run and the $\mathrm{KCl}$ solution inside the probe was able to mix with the simulant slurry. This event was not expected to have a significant impact on the SRAT processing chemistry. Caustic quenching of the slurry may have impacted the sulfate solubility. Total sulfate was approximately $1,400 \mathrm{mg} / \mathrm{kg}$ in all of the starting simulants.

A caustic-quenched slurry sample was taken in each run 30 minutes before the end of reflux to check for residual nitrite ion. SRAT product samples were taken and analyzed for 
elements, anions, solids, etc., but these samples were not caustic quenched and were not taken until the SRAT had cooled to below $50^{\circ} \mathrm{C}$ which was another hour or two after the power to the SRAT heating mantle had been turned off. Results are presented for the anions and the slurry $\mathrm{pH}$ in Table 6 . The end of reflux $\mathrm{pH}$ is from the $\mathrm{pH}$ probe in the SRAT vessel at about $101^{\circ} \mathrm{C}$, while the SRAT product sample $\mathrm{pH}$ is from a separate analytical probe used by PSAL on room temperature samples.

Table 6. Anion concentration, $\mathrm{mg} / \mathrm{kg}$, end of SRAT cycle

\begin{tabular}{|l|c|c|c|c|}
\hline & $\begin{array}{c}\text { Hi Fe- } \\
\text { Hi Mn }\end{array}$ & $\begin{array}{c}\text { Hi Fe- } \\
\text { Lo Mn }\end{array}$ & $\begin{array}{c}\text { Lo Fe- } \\
\text { Hi Mn }\end{array}$ & $\begin{array}{c}\text { Lo Fe- } \\
\text { Lo Mn }\end{array}$ \\
\hline Nitrite ion - product & 200 & $<100$ & 110 & $<100$ \\
\hline Nitrite ion - 11.5 hr reflux & 350 & 130 & 290 & $<100$ \\
\hline Formate ion - product & 51,400 & 48,900 & 51,100 & 47,300 \\
\hline Formate ion - 11.5 hr reflux & 53,400 & 50,600 & 52,200 & 48,800 \\
\hline Nitrate ion - product & 22,100 & 27,200 & 22,700 & 25,500 \\
\hline Sulfate ion - product & 200 & $<100$ & 770 & $<100$ \\
\hline SRAT pH, end of reflux & 5.7 & 5.5 & 6.1 & 5.7 \\
\hline SRAT product sample pH & 6.9 & 6.8 & 7.0 & 6.8 \\
\hline
\end{tabular}

The nitrite ion data trend exactly as in Table 5 with the two Hi Mn runs having more than the two Lo Mn runs, and the Lo Fe runs tending to have less than the corresponding Hi Fe runs. All runs had less than $1,000 \mathrm{mg} / \mathrm{kg}$ nitrite in the SRAT product indicating that $105 \%$ of the Koopman minimum stoichiometric acid equation was more than sufficient. This was the anticipated outcome of using the $105 \%$ factor rather than $100 \%$.

It was hoped that some of the runs would have nitrite between $1,000 \mathrm{mg} / \mathrm{kg}$ and the detection limit of $<100 \mathrm{mg} / \mathrm{kg}$ in order to evaluate the suitability of the selected stoichiometric factor. Three runs with detectable nitrite near the end of the SRAT cycle indicate that there was not much excess acid in these runs. The presence of some residual nitrite implies that the Koopman minimum acid equation was not significantly over-predicting the requirement to meet the nitrite destruction goal for those three simulations.

The fourth run, Lo Fe-Lo Mn, had 6-12\% more nitrite destruction by the end of acid addition than the other three runs. Faster nitrite destruction would seem to indicate that the $105 \%$ stoichiometric factor provided more excess acid to this run than the others, but that it was still relatively close to the other three in reaction rates. Data are insufficient to conclude whether it was random uncertainties in the acid equation inputs, or the minimum acid equation itself, that led to the slightly larger quantity of excess acid in the Lo Fe-Lo Mn run. GC data tend to support this conclusion, Section 4.7.

Both the hot and cold sets of SRAT product $\mathrm{pH}$ data fell in a fairly narrow range of values across the sludge matrix compositional variations. The room temperature readings are historically higher than the readings from the SRAT vessel at boiling for the SRAT product. 
Anion data were combined with material balance data. The resulting calculations were used to determine the extent of nitrite destruction, the amount of nitrite-to-nitrate conversion, and the extent of formate loss. The pre-run acid calculations were prepared assuming 100\% nitrite destruction, $30 \%$ nitrite-to-nitrate conversion, and $15 \%$ formate loss. The results of these calculations are given in Table 7.

Table 7. Anion reaction extents in SRAT cycle, $\%$

\begin{tabular}{|l|c|c|c|c|}
\hline & $\begin{array}{c}\text { Hi Fe- } \\
\text { Hi Mn }\end{array}$ & $\begin{array}{c}\text { Hi Fe- } \\
\text { Lo Mn }\end{array}$ & $\begin{array}{c}\text { Lo Fe- } \\
\text { Hi Mn }\end{array}$ & $\begin{array}{c}\text { Lo Fe- } \\
\text { Lo Mn }\end{array}$ \\
\hline Nitrite-to-nitrate conversion & 14 & 16 & 18 & 15 \\
\hline Nitrite destruction & 99 & 99 & 99 & 100 \\
\hline Formate loss & 19 & 16 & 17 & 15 \\
\hline $\mathrm{Fe}^{2+} / \mathrm{Fe}$ total & 0.22 & 0.23 & 0.24 & 0.24 \\
\hline
\end{tabular}

Uncertainties in the calculated formate loss and nitrite-to-nitrate conversion percentages due to propagation of potential random analytical and mass balance errors have been previously determined to be of order $10 \%$ in absolute terms, so a $15 \%$ nitrite-to-nitrate conversion is approximately $15 \pm 10 \%$. Consequently, the formate loss and nitrite-to-nitrate conversion values are too tightly grouped to detect any trends from the results of just four runs. Nitriteto-nitrate conversion, however, appears to have been less than assumed on average at about $17 \%$ actual versus $30 \%$ assumed. The result was a slightly more reducing predicted melter feed than planned. The primary conclusion is that the changing insoluble solids composition in the sludge matrix apparently had a minimal impact on these quantities at the low noble metal-low acid stoichiometry corner of the planned test matrix.

\subsection{ELEMENTAL AND DISSOLUTION DATA}

Elemental data was obtained for the SRAT product slurry, the SRAT product supernate, and also for SRAT slurry supernate immediately following formic acid addition. Certain species were found to have dissolved significantly by the end of formic acid addition. Information about supernate density, wt\% insoluble solids, etc. were combined with the ICP-AES supernate elemental concentration data in $\mathrm{mg}$ element/L supernate to determine the extent of dissolution of the species at the end of acid addition, Table 8.

Table 8. Extents of dissolution at the end of acid addition, $\%$

\begin{tabular}{|l|c|c|c|c|c|c|c|}
\hline & $\mathrm{Ca}$ & $\mathrm{Mg}$ & $\mathrm{Mn}$ & $\mathrm{Ni}$ & $\mathrm{Rh}$ & $\mathrm{Ru}$ & $\mathrm{S}$ \\
\hline Hi Fe-Hi Mn & 80 & 31 & 63 & 6 & $>100$ & 8 & 75 \\
\hline Hi Fe-Lo Mn & 78 & 65 & 58 & 24 & 73 & 16 & 37 \\
\hline Lo Fe-Hi Mn & 79 & 49 & 77 & 17 & 73 & 19 & 77 \\
\hline Lo Fe-Lo Mn & $>100$ & 87 & 92 & 50 & $>100$ & 31 & 63 \\
\hline
\end{tabular}

Calcium results were generally as expected from recent investigations into SRAT chemistry except for the Lo Fe-Lo Mn case where full dissolution was indicated. Magnesium results were not as expected. High initial $\mathrm{Mg}$ is found in the low Mn cases. The high $\mathrm{Mg}$ cases also 
had the most $\mathrm{Mg}$ dissolution in both relative and absolute terms. It would appear that some relatively insoluble $\mathrm{Mg}$ species may have formed in all four simulants, and that their presence is more significant relative to the total $\mathrm{Mg}$ in the two tests with less overall $\mathrm{Mg}$.

Manganese reduction as measured by manganese solubility was fairly well advanced by the end of acid addition. Reduction appeared to be proceeding slightly faster than nitrite destruction (58-92\% Mn reduction versus 46-62\% nitrite destruction). The Lo Fe-Lo Mn test with the highest percentage Mn reduction also had the most nitrite destruction by the end of acid addition. The Lo Fe-Hi Mn run had the greatest quantity of reduced Mn, since it started with about six times more than the low Mn simulants. Simply having less Mn did not necessarily mean that it would get reduced appreciably faster as evidenced by the Hi Fe-Lo Mn case which only had 58\% reduced (comparable in terms of moles reduced to about $10 \%$ in the high Mn cases).

Nickel was more soluble than expected for runs with low acid stoichiometries. Total Ni was high in the low Mn runs, and low in the high Mn runs. The solubility of Ni is very $\mathrm{pH}$ dependent, and it typically does not begin to dissolve until significant $\mathrm{Mn}$ reduction has occurred, which is often not until near the end of acid addition. The results above are not inconsistent with past findings, but it was somewhat surprising to see $50 \%$ of the $\mathrm{Ni}$ in the supernate of the Lo Fe-Lo Mn (high Ni) run. Nickel is believed to be present primarily as $\mathrm{Ni}(\mathrm{OH})_{2}$, so dissolution of significant $\mathrm{Ni}$ occurs with acid consumption of the liberated hydroxide ion. Current stoichiometric acid equations do not include nickel as a source term.

All four runs showed significant (near total) dissolution of $\mathrm{Rh}$ at the end of the formic acid addition. Current thinking is that the $\mathrm{Rh}$ is probably present as a hexa-nitro $\mathrm{Rh}$ complex, $\mathrm{Rh}\left(\mathrm{NO}_{2}\right)_{6}{ }^{3-}$, when the ratio of nitrite to $\mathrm{Rh}$ is very large (when nitrite is in the 1000's of $\mathrm{mg} / \mathrm{kg}$ ). Significant Ru was also in the supernate following acid addition. Concentrations of the two were fairly similar at about $4-8 \mathrm{mg} / \mathrm{L}$.

Sulfur, presumably as the sulfate ion since that is how it was introduced to the simulant, was detected at higher concentrations by ICP-AES than sulfate ion was by IC. The ICP-AES data are believed to be more robust in this case due to some peak interferences on the IC column. In any case, a quarter to over half of the sulfate was not detected in the supernate following acid addition and was presumably in the insoluble solids.

A similar set of analyses was performed on the supernates from the four SRAT product samples. The results of equivalent calculations on extent of elemental dissolution are given in Table 9. 
Table 9. Extents of dissolution at the end of SRAT cycle, \%

\begin{tabular}{|l|c|c|c|c|c|c|c|}
\hline & $\mathrm{Ca}$ & $\mathrm{Mg}$ & $\mathrm{Mn}$ & $\mathrm{Ni}$ & $\mathrm{Rh}$ & $\mathrm{Ru}$ & $\mathrm{S}$ \\
\hline Hi Fe-Hi Mn & 84 & 48 & 25 & $<1$ & $<15$ & $<4$ & 69 \\
\hline Hi Fe-Lo Mn & 70 & 75 & 25 & $<1$ & $<15$ & $<4$ & 28 \\
\hline Lo Fe-Hi Mn & 81 & 64 & 56 & $<1$ & $<15$ & $<4$ & 71 \\
\hline Lo Fe-Lo Mn & 78 & 72 & 57 & $<1$ & $<15$ & $<4$ & 40 \\
\hline
\end{tabular}

Calcium dissolution extent remained near $80 \%$. Magnesium extent of dissolution increased in the first three runs relative to the end of acid addition. Manganese extent of dissolution was lower in the high iron runs than in the low iron runs in both the end of acid addition and end of SRAT cycle samples, but the data indicate some precipitation of Mn during boiling in all four runs. Nearly all of the soluble nickel had precipitated by the end of the SRAT, as had most of the soluble $\mathrm{Rh}$ and $\mathrm{Ru}$. The extent of sulfur dissolution remained in the high-lowhigh-low pattern of Table 8 though significantly less remained in solution in the Lo Fe-Lo $\mathrm{Mn}$ run compared to the sample immediately after acid addition. Although Ni was high in the Lo Mn runs with reduced sulfate solubility, and a significant fraction was dissolved by the end of acid addition, the solubility data for $\mathrm{NiSO}_{4}$ indicate that it is unlikely to be the species simultaneously responsible for the low sulfate and nickel solubility in the SRAT product. $\mathrm{CaSO}_{4}$ has much lower solubility than $\mathrm{NiSO}_{4}$, and total $\mathrm{Ca}$ is higher in the $\mathrm{Hi} \mathrm{Mn}$ runs. Lower total $\mathrm{Ca}$ seems to be correlated with lower extents of $\mathrm{Ca}$ and $\mathrm{S}$ dissolution. Therefore $\mathrm{CaSO}_{4}$ is a potential candidate for explaining the sulfate/sulfur dissolution data.

\subsection{MERCURY}

Three samples were obtained for mercury analysis in each run. The new technique of pulling small slurry samples directly into digestion vials was used for all twelve samples to eliminate potential sub-sampling errors. This technique seems to provide repeatable results. One sample was pulled following dewatering, while the other two were pulled at the end of the SRAT cycle as the slurry was cooling. The data were converted back to ppm in the slurry and are given in Table 10. If no mercury stripping occurred, the $\mathrm{Hg}$ concentration after dewatering and in the SRAT product would be about $3800 \mathrm{mg} / \mathrm{kg}$.

Table 10. Sample results for total slurry $\mathrm{Hg}, \mathrm{mg} / \mathrm{kg}$

\begin{tabular}{|l|c|c|c|c|}
\hline & $\begin{array}{c}\text { After } \\
\text { dewater }\end{array}$ & $\begin{array}{c}\text { SRAT } \\
\text { product-1 }\end{array}$ & $\begin{array}{c}\text { SRAT } \\
\text { product-2 }\end{array}$ & $\begin{array}{c}\text { Average } \\
\text { product }\end{array}$ \\
\hline Hi Fe-Hi Mn & 3740 & 2780 & 2770 & 2780 \\
\hline Hi Fe-Lo Mn & 3390 & 180 & 170 & 180 \\
\hline Lo Fe-Hi Mn & 410 & 340 & 250 & 300 \\
\hline Lo Fe-Lo Mn & 2890 & 2860 & 2850 & 2860 \\
\hline
\end{tabular}

The first observation was that SRAT product $\mathrm{Hg}$ results were replicated very well on duplicate independent SRAT product samples with different dilution factors. Reproducibility has been one of the issues with $\mathrm{Hg}$ analyses in the past. The new sampling method, which 
goes directly from the SRAT into an aqua regia digestion vial, apparently eliminates some of the steps where $\mathrm{Hg}$ was being preferentially segregated.

It was observed during clean up that there was significant elemental mercury coating the bottom of the SRAT of the Hi Fe-Lo Mn run. It is unlikely that the $180 \mathrm{mg} / \mathrm{kg}$ result indicates that $95 \%$ of the mercury was actually steam stripped into the Mercury Water Wash Tank (MWWT). Such a high removal efficiency would greatly exceed expectations based on historical stripping data. The Lo Fe-Hi Mn run was much more viscous than the other three. It is suspected that local velocities were not high enough to hold elemental mercury in the slurry, and that the entire row of results represent under reporting of the actual mercury in the vessel. The data from the other two runs indicate fairly inefficient stripping of the mercury with nearly $75 \%$ of the initial mercury remaining in the slurry to be sampled with the SRAT product.

Approximately 3,300 grams of condensate were boiled off during dewatering and reflux to remove less than 3 grams of $\mathrm{Hg}$ in both the first and fourth run. This $1100 \mathrm{~g}$ condensate $\mathrm{g}$ $\mathrm{Hg}$ rate is much less efficient than the 500-750 g condensate/g $\mathrm{Hg}$ rate expected from historical data. It is possible that the low mercury removal efficiency is somehow linked to the low acid stoichiometry. SB5 flowsheet testing showed reduced mercury stripping efficiencies at low acid stoichiometries for both the Tank 51 and Tank 40 simulants. ${ }^{7}$ Similar trends were observed again in the preliminary SB6 simulant testing at the two wash endpoint compositions that were studied. ${ }^{8}$ Conversely, no clear trend was observed in SB4 simulant flowsheet testing, ${ }^{9}$ although the qualification simulant testing data may have supported the trends seen in the SB5 and SB6 studies. ${ }^{10}$ The four completed sludge matrix tests are all low acid stoichiometry tests, and the poor mercury stripping efficiency seen here may be supporting the hypothesis that there is a relationship between acid stoichiometry and mercury stripping efficiency. Proposed future tests with the four matrix simulants trimmed with low noble metal concentrations using high acid stoichiometry are needed to support or refute the hypothesis. The eight planned high noble metal tests with low and high acid stoichiometry offer another block of results that could support this hypothesis.

About $50 \mathrm{~g}$ of condensate plus elemental mercury was recovered from the MWWT at the end of the SRAT cycle. The Lo Fe-Hi Mn sample contained about half as much elemental $\mathrm{Hg}$ as the other three. This observation is not consistent with the low slurry analysis on the aqua regia digested SRAT sample which suggests that 2-3 times more $\mathrm{Hg}$ was stripped in the Lo $\mathrm{Fe}-\mathrm{Hi} \mathrm{Mn}$ run than in the Hi Fe-Hi Mn and Lo Fe-Lo Mn runs. The amount of recovered mercury from the MWWT in the Hi Fe-Hi Mn run was about two grams, or about $20 \%$ of the initial charge. This mass was consistent with the analytical result that about $75 \%$ of the initial $\mathrm{Hg}$ was still in the SRAT. The amounts of $\mathrm{Hg}$ recovered from the MWWT in the Hi Fe-Lo Mn and Lo Fe-Lo Mn runs were also about two grams, while the Lo Fe-Hi Mn recovery was about half this amount. Consequently, any analytical result in Table 10 under $2,000 \mathrm{mg} / \mathrm{kg}$ can potentially be considered suspect from a mercury balance standpoint. The primary cause appears to be the formation of a segregated SRAT slurry, i.e. a slurry with compositional gradients within the vessel, that can not be sampled in a representative manner for $\mathrm{Hg}$. 


\subsection{AMMONIUM PRODUCTION}

The lab-scale SRAT has a chilled water condenser (FAVC) in the off-gas line after the SRAT condenser to remove additional moisture upstream of the GC sample point. A small quantity of condensate accumulates in the bottom of the condenser during the SRAT cycle. This condensate is generally quite acidic making it an ideal point to check for ammonia production in the off-gas system of the lab-scale SRAT. The four condensates from the four runs were submitted to Analytical Development for cation chromatography. The mass of condensate and the ammonium ion concentration are given in Table 11.

Table 11. Sample results for ammonium in the chilled condensate, $\mathrm{mg} / \mathrm{L}$

\begin{tabular}{|l|c|c|c|c|}
\hline & $\begin{array}{c}\text { Condensate } \\
\text { mass, } \mathrm{g}\end{array}$ & $\begin{array}{c}\text { Ammonium } \\
\text { conc., mg/L }\end{array}$ & $\begin{array}{c}\text { One sigma } \\
\text { Uncertainty }\end{array}$ & $\begin{array}{c}\text { Total } \\
\mathrm{NH}_{3}, \mathrm{mg}\end{array}$ \\
\hline Hi Fe-Hi Mn & 18.76 & 4 & $10 \%$ & 0.055 \\
\hline Hi Fe-Lo Mn & 32.84 & 6 & $10 \%$ & 0.143 \\
\hline Lo Fe-Hi Mn & 19.12 & 5 & $10 \%$ & 0.069 \\
\hline Lo Fe-Lo Mn & 25.19 & 8 & $10 \%$ & 0.146 \\
\hline
\end{tabular}

The total ammonium mass in the chilled condensate was calculated assuming an approximate density of $1.3 \mathrm{~g} / \mathrm{mL}$ which is consistent with historical results and sufficiently accurate for the calculations being made. Ammonia evolution did appear to be slightly favored in the pair of low manganese runs relative to the two high manganese runs. Ultimately, however, the values for total ammonia evolved and captured in the condensate indicated a very small production rate. Therefore, the SRAT product slurries were not analyzed for ammonium ion content. Note that it is postulated that ammonia formation may be a catalytic reaction involving nitrate ion occurring primarily during reflux in the SRAT cycle, and that the catalysts were not particularly active in this group of four low noble metal concentration-low total acid SRAT simulations. There are about $80 \mathrm{~g}$ of nitrate in the individual SRAT products, so less than $1 \%$ of the available nitrate was converted to ammonia. It will be interesting to compare these results to the high noble metal-high total acid result from the planned future runs in the sludge matrix study.

\subsection{PROBE DATA}

Data on the $\mathrm{pH}$ of the SRAT slurry during processing were obtained in all four runs. Data on the oxidation-reduction potential (ORP) of the SRAT supernate were obtained on the Lo Fe$\mathrm{Hi} \mathrm{Mn}$ and the Lo Fe-Lo Mn runs. Data on $\mathrm{pH}$ profiles for the two high manganese runs are given in Figure 1. 


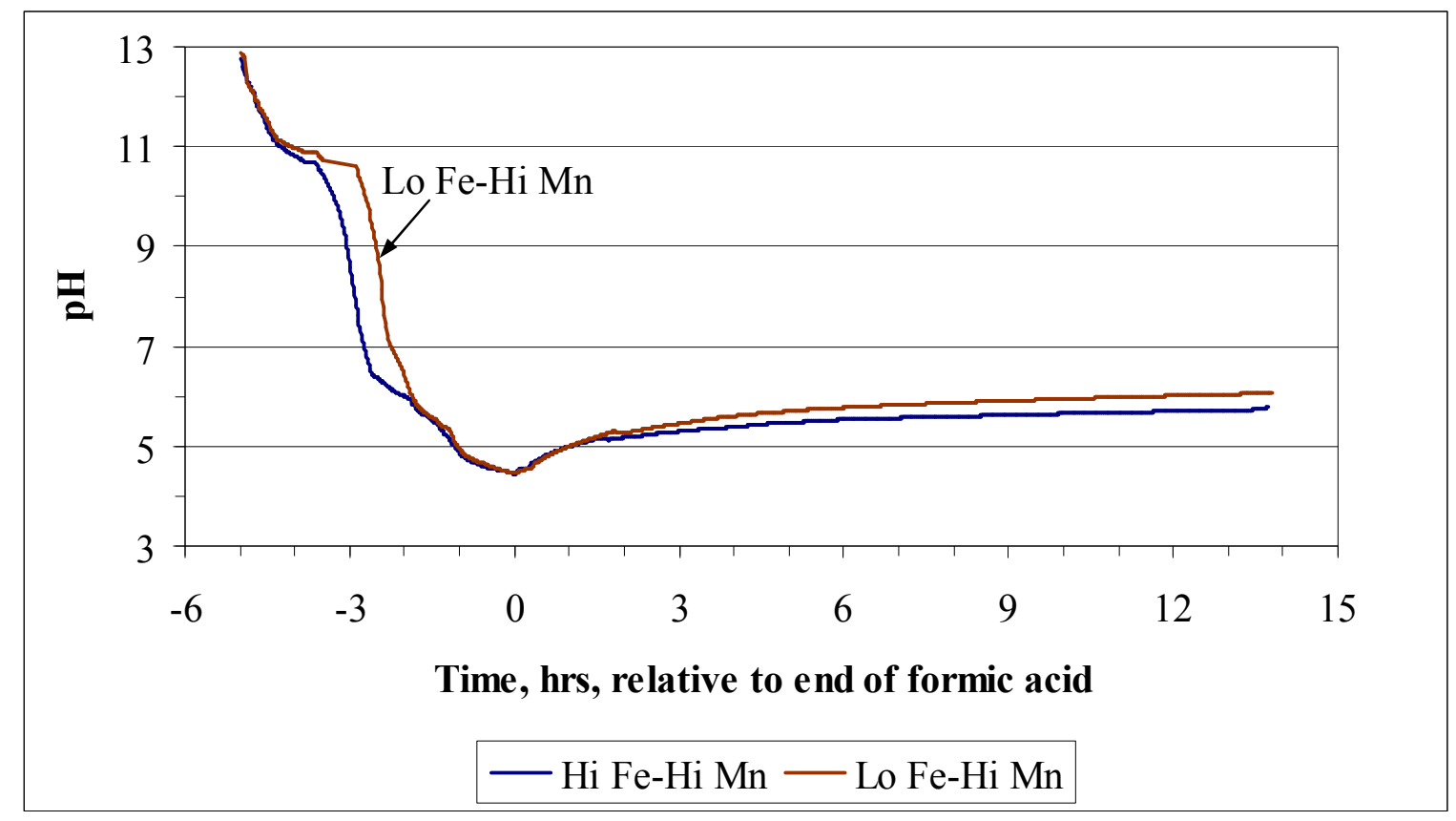

Figure 1. Hi Mn run $\mathrm{pH}$ probe data

The $\mathrm{pH}$ probe broke in the Lo Fe-Hi Mn run and was replaced during the period of about -3.3 to -2.8 hours (during formic acid addition). Formic acid was paused to make the replacement which may explain the offset in the two curves between two and three hours before the end of formic acid addition. All four simulations reached $\mathrm{pH}$ values in the 4.25-4.50 range at the end of acid addition. This condition has generally indicated that nitrite will be destroyed to below the DWPF SRAT product limit by the end of the SRAT cycle unless oxalate concentrations are unusually high, for example greater than $10,000 \mathrm{mg} / \mathrm{kg}$ in the case of SB3.

Both $\mathrm{pH}$ and ORP probe data were obtained on the two low manganese runs. The data from the Hi Fe-Lo Mn run are given in Figure 2. The ORP probe reading is in relative millivolts. 


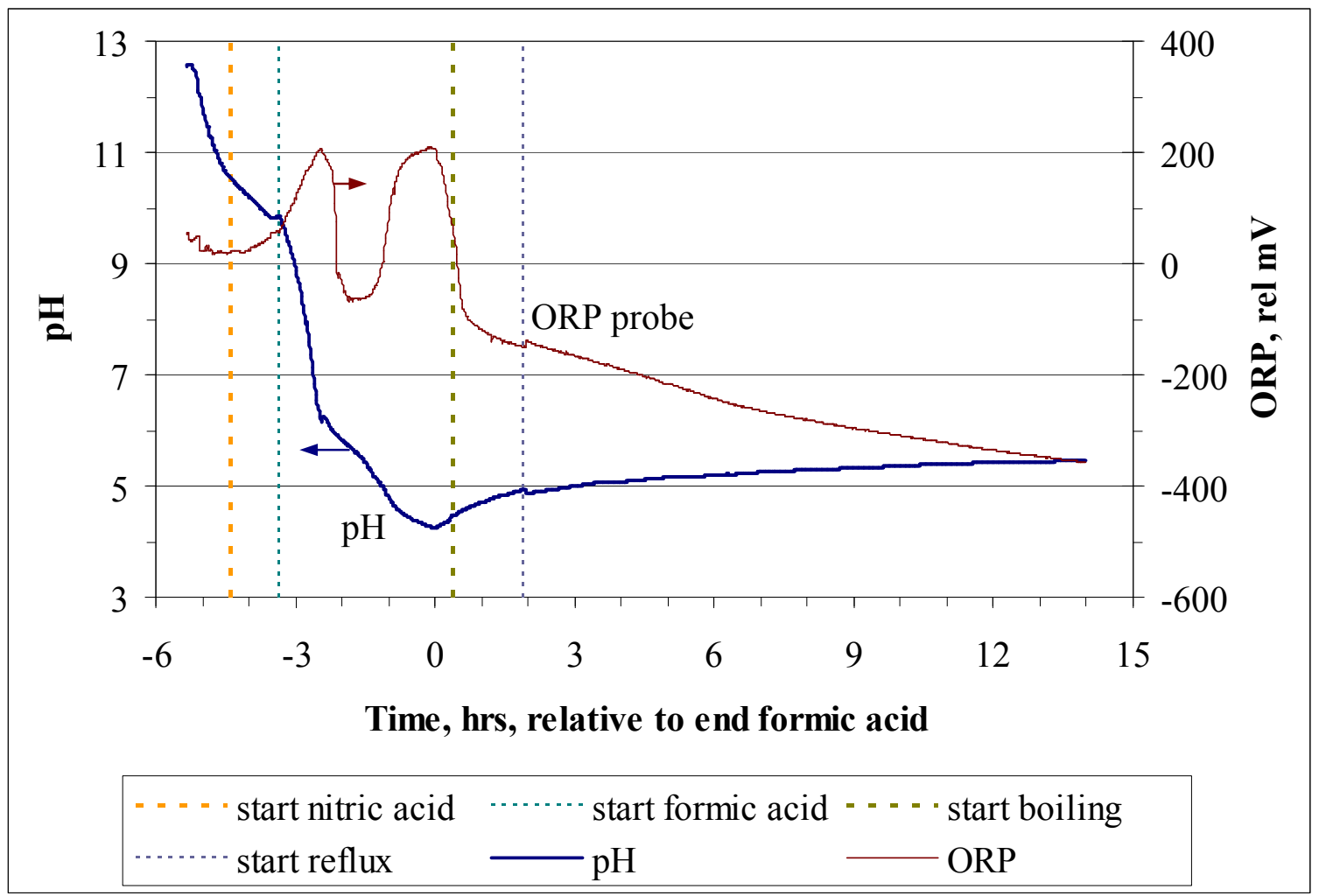

Figure 2. ORP and pH probe data for the Hi Fe-Lo Mn run

The ORP probe was checked against two "standard solutions". The nominal ORP potentials of the standard solutions are uncertain by $\pm 10 \%$. The ORP probe was reading high by $30-60$ $\mathrm{mV}$ relative to the standards. Two large features were seen in the ORP data during and shortly after acid addition. The slurry appeared to be slightly reducing in relative millivolts initially and during nitric acid addition, but was probably slightly oxidizing due to the bias high in the relative millivolt readings. The supernate went reducing during the early part of formic acid addition. When the slurry went acidic, the ORP trend reversed, and the potential became oxidizing. The ORP subsequently recovered and went back reducing as formic acid continued. When formic acid addition stopped, the potential started trending back toward more oxidizing values. This trend continued until the end of the SRAT cycle. The ORP potential was expected to fall during periods of heating, such as between acid addition and dewatering. The size of the observed change, however, is much greater than the Nernst equation would predict indicating that other chemical processes are occurring during temperature changes.

The data from the Lo Fe-Lo Mn run are given in Figure 3. 


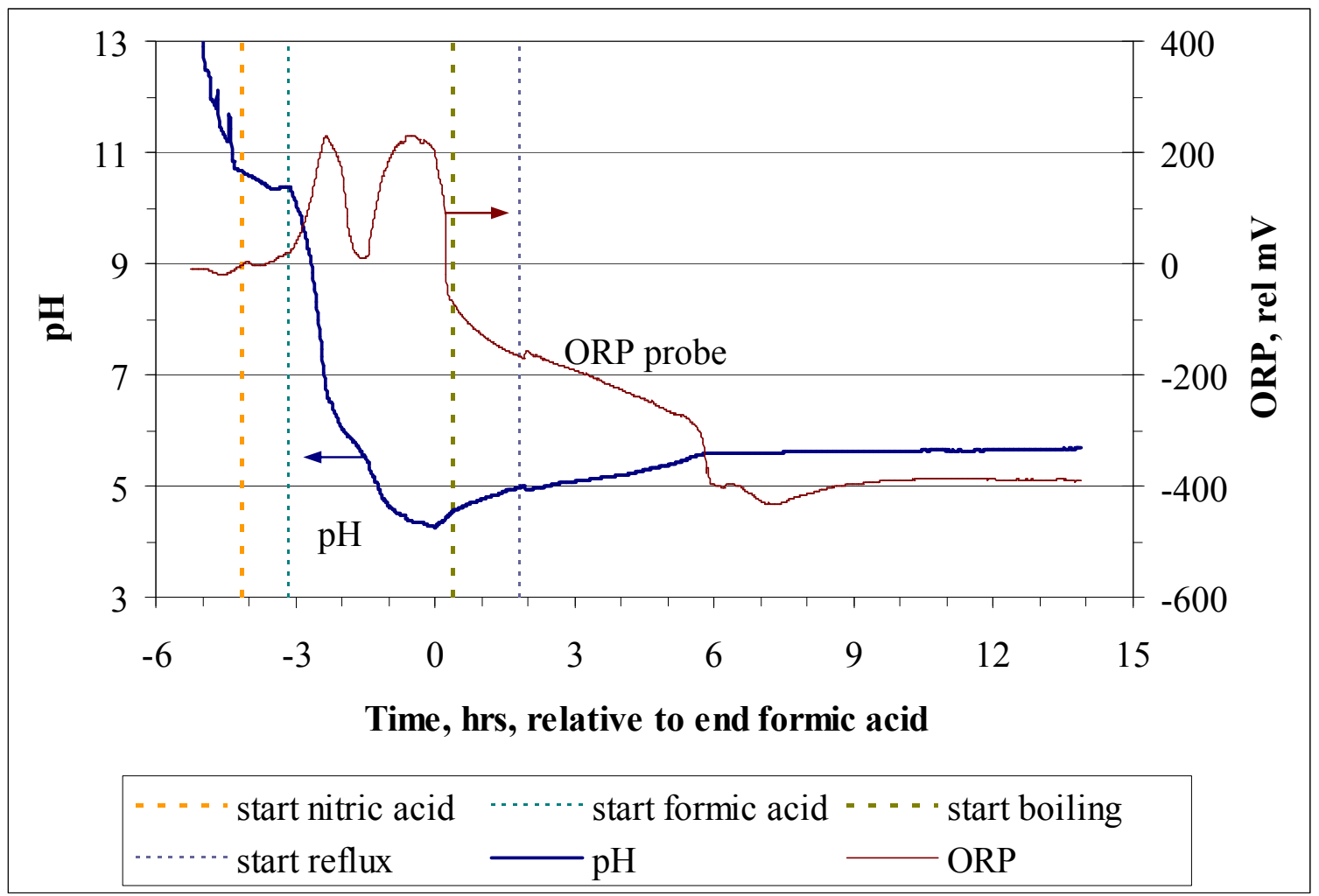

Figure 3. ORP and pH probe data for the Lo Fe-Lo Mn run

The ORP probe data for the Lo Fe-Lo Mn run was generally similar to the Hi Fe-Lo Mn run data. This includes the readings obtained in the standard solutions. The two large features during formic acid addition were seen again. The only significant difference appeared at about six hours after acid addition where there was a significant drop in the Lo Fe-Lo Mn run, while the Hi Fe-Lo Mn run had a steady decline. Hydrogen was detected in the Lo FeLo Mn run at about eight hours after formic acid addition. (Hydrogen was not detected in the Hi Fe-Lo Mn run.) Both ended near -400 relative $\mathrm{mV}$ at the end of the SRAT cycle.

The two sets of ORP data are compared to each other directly in Figure 4. 


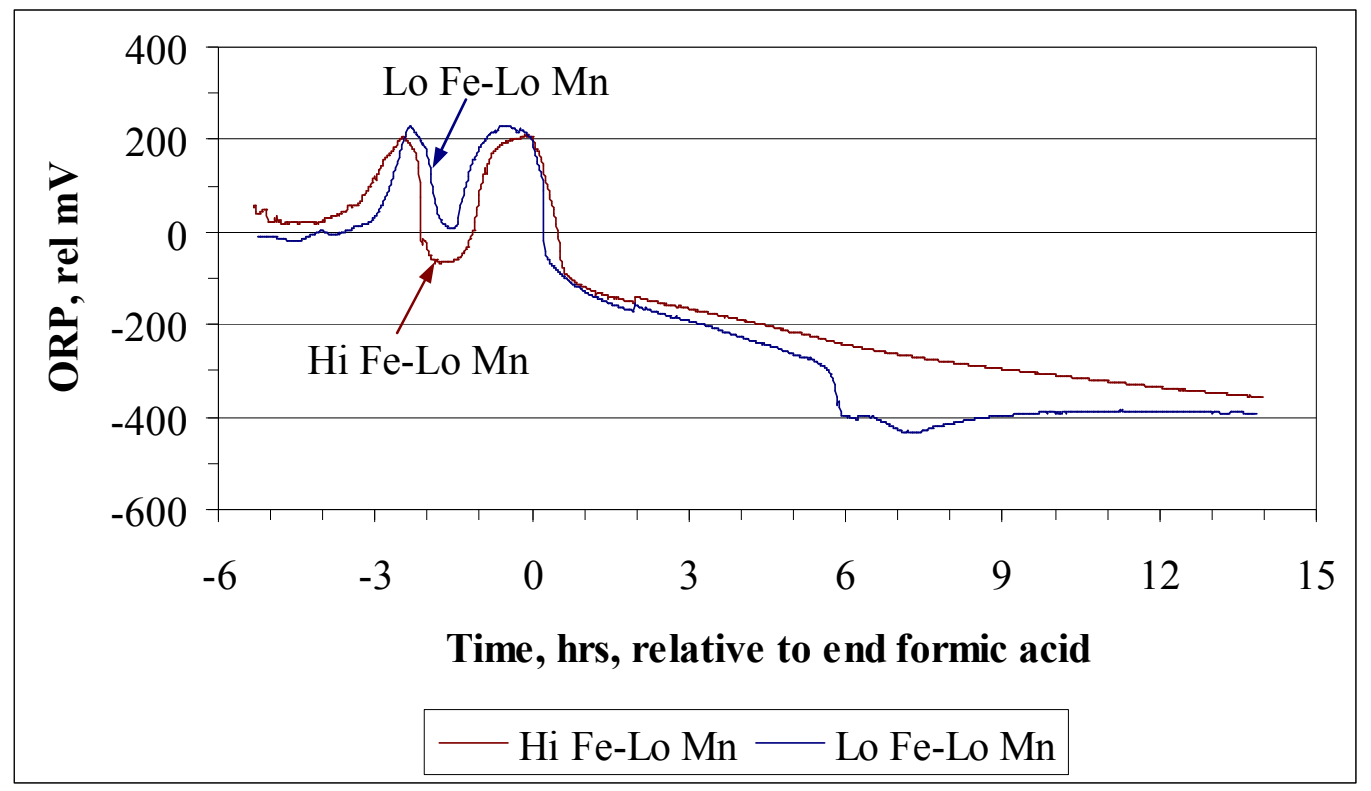

Figure 4. Comparison of Hi Fe and Lo Fe ORP data at Lo Mn

The comparison plot shows that the two features that were seen during acid addition are quite similar but not identical. The valley between the two peaks was broader during the Hi Fe-Lo $\mathrm{Mn}$ run than the Lo Fe-Lo Mn run. The plan is to continue to collect ORP probe data on selected future SRAT simulations and to build an ORP profile database with the goal of assigning specific reactions to the changes being seen.

Several earlier sets of ORP data have shown a drop in potential as $\mathrm{pH}$ fell below seven in tests with significant $\mathrm{Hg}$, so this loss of accumulated reducing potential may correspond to the reduction of mercury reaction. There are some runs, however, that do not show this first peak and drop that do have $\mathrm{Hg}$ present. Therefore the data are still inconclusive at this point. It seems likely that the second peak in the ORP data is somehow related to catalytic nitrite destruction (a reduction reaction), $\mathrm{MnO}_{2}$ reduction, or both.

\subsection{RHEOLOGICAL DATA}

The four SRAT products were characterized using the Haake RS600 rheometer at ACTL. Duplicate flow curves were obtained over the shear rate range of $0-600 / \mathrm{sec}$ for each product. An example of the data obtained is given in Figure 5 for the Hi Fe-Lo Mn SRAT product. 


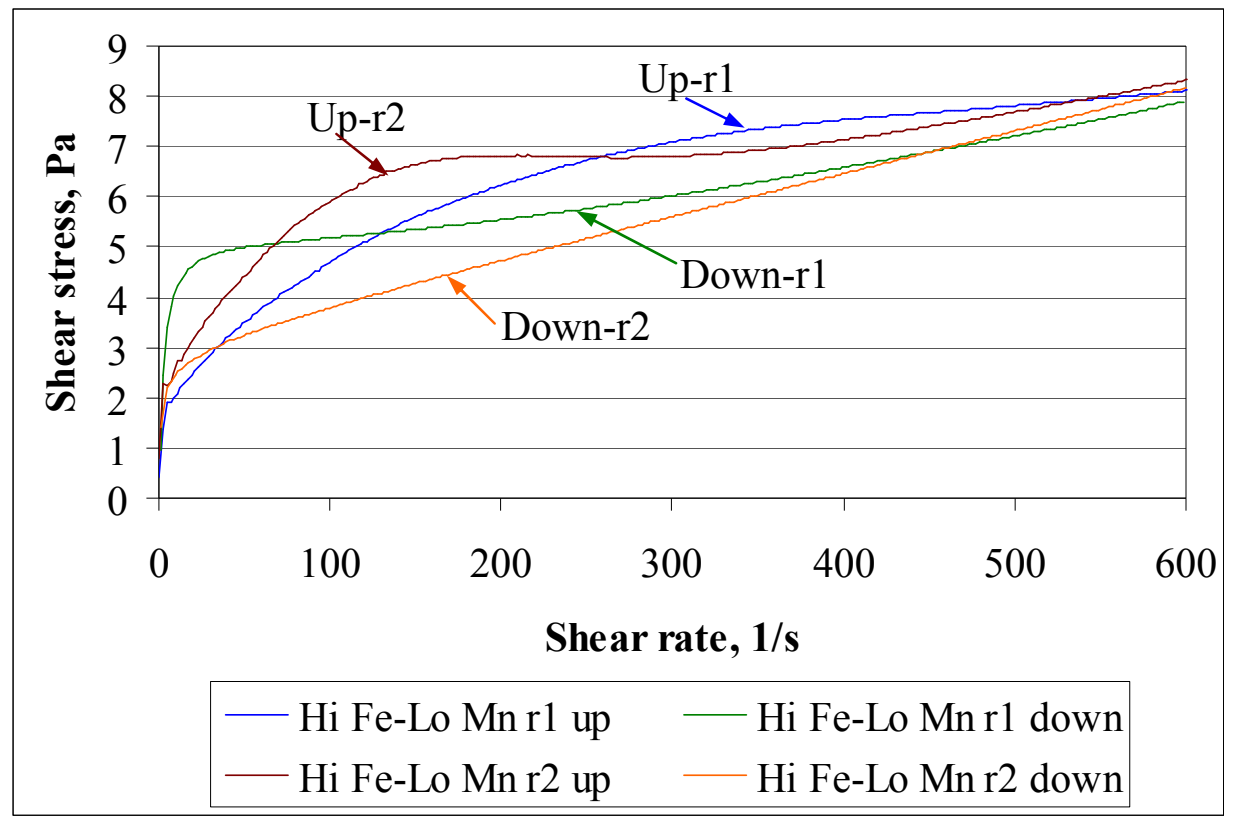

Figure 5. Flow curve data for the Hi Fe-Lo Mn SRAT product

The up flow curves were not uniformly bowed in the replicate measurements. The two down flow curves were also qualitatively different in appearance. This behavior was typical of all four SRAT products, that is, there were indications of sustained (time dependent) structure in the simulants after mixing the samples and loading the rheometer that interfered with getting high reproducibility in the flow curve measurements. Additional flow curve data are given in Appendix A.

Flow curves were fit on the interval 100-600/s shear rate in order to determine the Bingham plastic yield stress and consistency. Both up curve and down curve data were fit. Results are summarized in Table 12.

Table 12. SRAT product Bingham plastic model results

\begin{tabular}{|l|c|c|c|c|c|}
\hline & $\begin{array}{c}\text { Wt \% } \\
\text { Insoluble } \\
\text { Solids }\end{array}$ & $\begin{array}{c}\text { Up Yield } \\
\text { Stress, Pa }\end{array}$ & $\begin{array}{c}\text { Up } \\
\text { Consistency, } \\
\text { cP }\end{array}$ & $\begin{array}{c}\text { Down Yield } \\
\text { Stress, Pa }\end{array}$ & $\begin{array}{c}\text { Down } \\
\text { Consistency, } \\
\text { cP }\end{array}$ \\
\hline Hi Fe-Hi Mn & 16.4 & 2.4 & 7.6 & 2.3 & 6.1 \\
\hline Hi Fe-Lo Mn & 15.1 & 5.5 & 4.7 & 3.7 & 7.1 \\
\hline Lo Fe-Hi Mn & 13.1 & 34 & 13.4 & 42 & 0.34 \\
\hline Lo Fe-Lo Mn & 15.0 & 6.4 & 6.4 & 5.2 & 8.4 \\
\hline
\end{tabular}

The Hi Fe-Hi Mn case had the highest wt \% insoluble solids, but it had the least viscous behavior. The two low iron cases had higher yield stresses than the two high iron cases, which is consistent with historical data indicating that HM sludges are more viscous than Purex sludges. The Lo Fe-Hi Mn case was the least like the other three. It had nearly an order of magnitude higher yield stress for both the up and down curve fits in spite of having 
the lowest wt \% insoluble solids. The Lo Fe-Lo Mn case may have received a little more acid in a relative sense (based on nitrite destruction results) which should have helped to thin it out some relative to the others, but it was the second most viscous of the four products. More rheological data from the rest of the planned matrix study will help to clarify the trends.

\subsection{OFF-GAS DATA}

GC data were obtained during portions of all four runs. The first two SRAT simulations had all of the process and GC data coming to the desktop control and data acquisition computer through an Ethernet hub. This volume of traffic appeared to interfere with the operation of the Agilent Cerity software controlling the two GCs. It was noted periodically that the two GCs had stopped sampling during the initial 5-8 hours of the simulations. Instructing the GCs to resume sampling was problematic in at least one instance (GC did not resume sampling as instructed). Consequently, it was decided to switch the GCs from the desktop computer to individual laptop computers while the runs were in progress. Additional gaps in the data were caused by the changeover.

By the end of the first pair of simulations, it was apparent that the $\mathrm{B}$ column measuring $\mathrm{CO}_{2}$ and $\mathrm{N}_{2} \mathrm{O}$ on the $\mathrm{GC}$ for the $\mathrm{Hi} \mathrm{Fe}-\mathrm{Hi} \mathrm{Mn}$ run had stopped working (peaks were extremely small suggesting insufficient sample was reaching the column). This GC was replaced with a spare GC prior to the second pair of runs. The only available spare, however, had an internal back flush feature that eluted in the region where helium and hydrogen elute. This caused an initially large uncertainty in the accuracy of the helium internal standard concentration. Nominal $0.5 \mathrm{vol} \%$ readings ranged from $0.3-1.2 \%$ depending on where the peak eluted on the back flush and how the software performed the peak area integration. The run impacted was the Lo Fe-Hi Mn SRAT simulation. During reprocessing of the chromatographs, it was possible to use an advanced baseline integration technique in the software to stabilize the peak integrations. Consequently it was still possible to calculate reasonably smooth curve production rates of $\mathrm{CO}_{2}$ and $\mathrm{N}_{2} \mathrm{O}$ using the He flow after the run.

The $\mathrm{CO}_{2}$ generation rate data from three of the four runs are given in Figure 6. The plot for the Hi Fe-Lo Mn run (blue) data contains gaps where the GC had stopped sampling. The Hi $\mathrm{Fe}-\mathrm{Hi} \mathrm{Mn}$ test did not obtain useful $\mathrm{CO}_{2}$ or $\mathrm{N}_{2} \mathrm{O}$ data due to the column sampling issue. 
SRNL-STI-2009-00606, REVISION 0

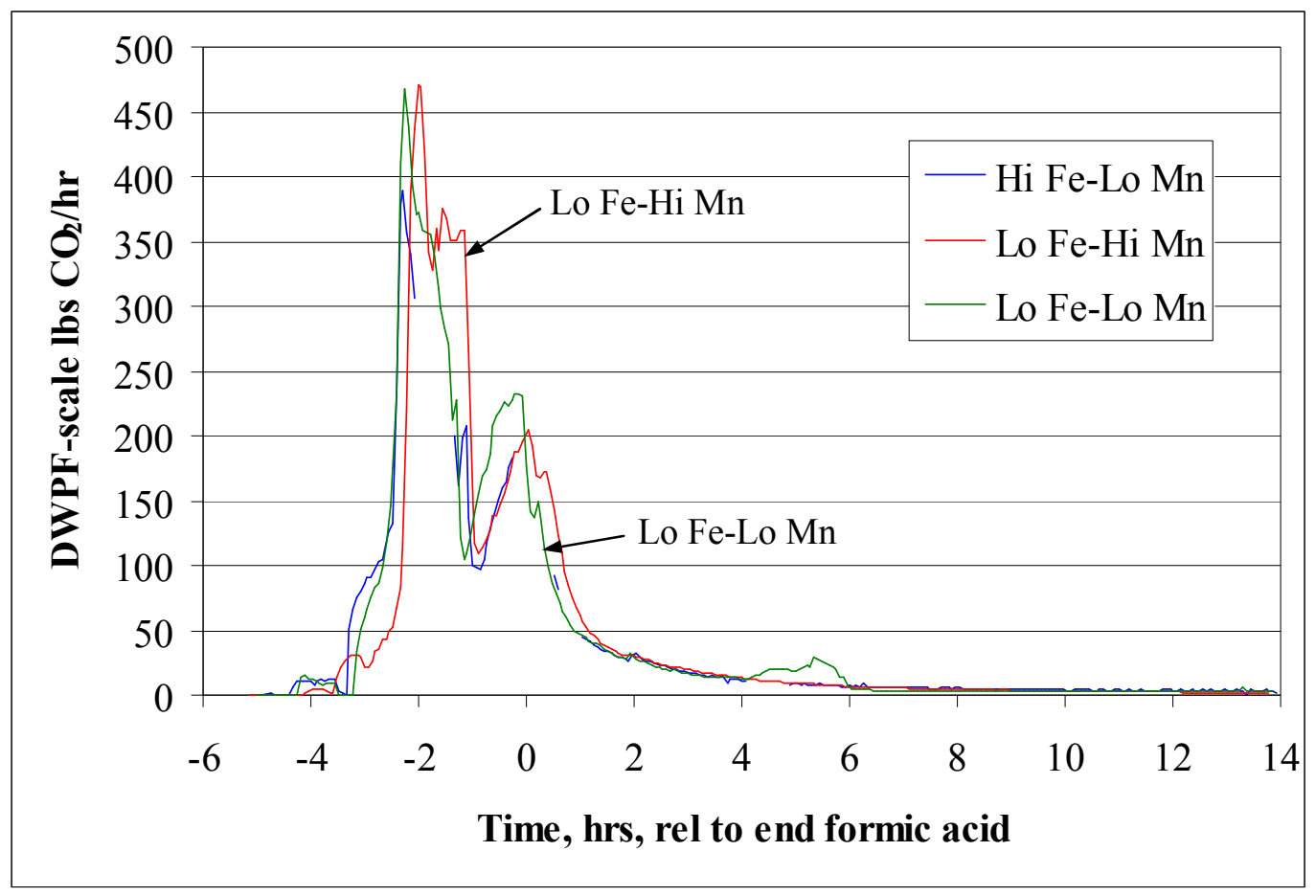

Figure 6. Composite carbon dioxide GC data converted to DWPF scale flow

The high manganese runs were expected to produce more $\mathrm{CO}_{2}$ than the low manganese runs due to the $\mathrm{CO}_{2}$ production that occurs during reduction. The period of 1-1.5 hours before the end of formic acid addition shows relatively higher $\mathrm{CO}_{2}$ production for the one high $\mathrm{Mn}$ run than the two low Mn runs, but the differences are not large. The Lo Fe-Lo Mn run seems to be coming out of nitrite destruction sooner than the Lo Fe-Hi Mn run and perhaps slightly sooner than the Hi Fe-Lo Mn run. This would be consistent with the Lo Fe-Lo Mn run receiving slightly more acid than necessary compared to the other runs. An interesting feature occurred between 4-6 hours after acid addition in the Lo Fe-Lo Mn data. This feature was also seen in the $\mathrm{N}_{2} \mathrm{O}$ data which are given in Figure 7. 
SRNL-STI-2009-00606, REVISION 0

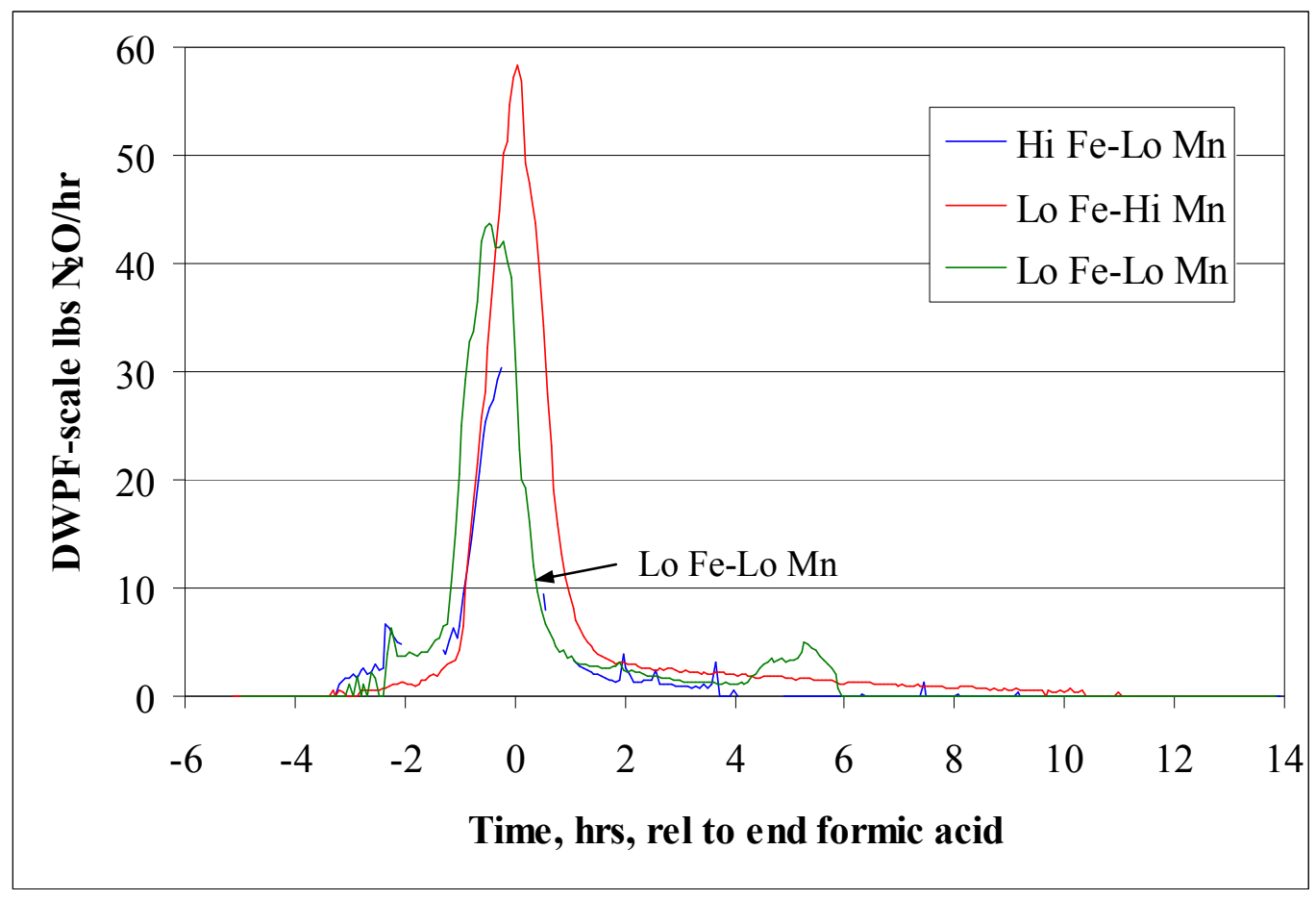

Figure 7. Composite nitrous oxide GC data converted to DWPF scale flow

The $\mathrm{N}_{2} \mathrm{O}$ data, like the $\mathrm{CO}_{2}$ data, suggest that nitrite destruction completed relatively sooner in the Lo Fe-Lo Mn run than in the Lo Fe-Hi Mn run. This could indicate that less acid should have been added to the Lo Fe-Lo Mn run. It is also possible that the generally larger $\mathrm{CO}_{2}$ production rate peak in the Lo Fe-Hi Mn run created a larger inventory of $\mathrm{N}_{2} \mathrm{O}$ in the system that required more time to pass out the off-gas line to the GC. At least some of the 20-30 minute lag between the two runs should be attributable to the difference in the process dynamic response of the systems. Aligning the curves by changing the acid stoichiometry would require roughly a 5-10\% change in total acid. The Hi Fe-Lo Mn run data does not appear to lag the Lo Fe-Lo Mn data by much (at about +0.45 hours), but only a few GC scans were obtained in the relevant period.

The consumption of oxygen during nitrite destruction was converted into an equivalent flow of $\mathrm{NO}_{2}$ gas (equivalently $\mathrm{N}_{2} \mathrm{O}_{4}$ gas in mass flow units). The results of these calculations are given in Figure 8. 
SRNL-STI-2009-00606, REVISION 0

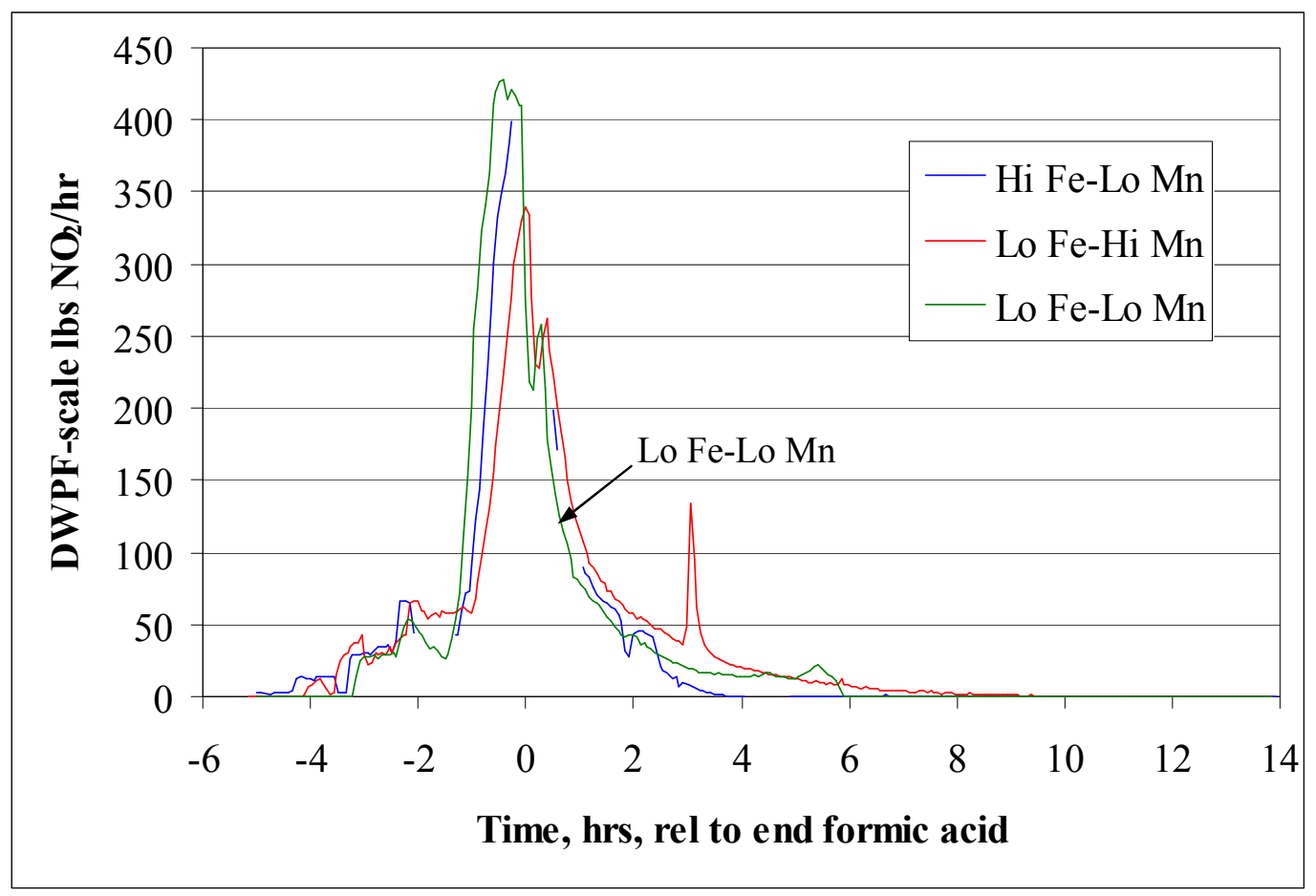

Figure 8. Composite of the derived $\mathrm{NO}_{2}\left(\mathrm{~N}_{2} \mathrm{O}_{4}\right)$ generation rates

The calculations indicate that $\mathrm{NO}_{2}$ production was higher in the two runs with lower $\mathrm{N}_{2} \mathrm{O}$ production which is unlikely to be coincidental. The three runs should have identical starting nitrite concentrations, so when more $\mathrm{N}_{2} \mathrm{O}$ is made there is less nitrite left over for $\mathrm{NO}_{2}$ and vice versa. The $\mathrm{NO}_{2}$ production period seemed to start and end sooner for the Lo Fe-Hi Mn run in these data also, again suggesting that somewhat more excess acid was added compared to the other two runs.

A small chromatograph peak indicating the presence of low concentrations of NO in the offgas is usually seen during nitrite destruction. This peak is caused by NO not converted into $\mathrm{NO}_{2}$. The $\mathrm{NO}$ is a by-product of nitrite destruction. Current cal gas compositions do not include NO, since it is incompatible with oxygen. The off-gas outlet flow rates of NO have generally been roughly an order of magnitude less than those for $\mathrm{NO}_{2}$ in typical SRAT simulations. The relative proportions of $\mathrm{NO}$ to $\mathrm{NO}_{2}$ should be affected by equilibrium relationships involving oxygen and temperature as the other significant variables, and the proportions should not change much under lab-scale SRAT operating conditions. Therefore, it is somewhat surprising that virtually no NO was detected during the Lo Fe-Hi Mn SRAT cycle. Relatively typical NO exhaust levels were seen in the GC off-gas data from the other two runs. The main question is why there was no peak for $\mathrm{NO}$, since $\mathrm{NO}_{2}$ production was plentiful, and one gas should not be present without the other when oxygen is present. This situation will be monitored in future tests with the sludge matrix study simulants.

Hydrogen was not detected in the two high Fe runs or in the Lo Fe-Hi Mn run. The Lo FeLo Mn run GC detected a maximum hydrogen concentration of $0.008 \mathrm{vol} \%$ near the end of the SRAT cycle $(0.0067 \mathrm{lb} / \mathrm{hr}$ at DWPF scale versus the $0.65 \mathrm{lb} / \mathrm{hr}$ SRAT limit) suggesting 
that there was a little more excess acid in this run than in the other three runs. Other data from the runs (discussed earlier in this section) support the hypothesis that the Lo Fe-Lo Mn run was fed slightly more excess acid than the other three runs.

Nafion dryers have been installed in the two 4L lab-scale off-gas systems downstream of the chilled condenser and upstream of the sampling tee to the GC. They were used during these tests. The dryers were installed to reduce the likelihood of forming nitric or nitrous acids inside the GC. The dryers were configured as a counter-current tube-in-tube mass exchanger with the SRAT off-gas passing through the center tube. Compressed air that had been passed through a Drier-rite column was set up as the counter-current purge in the outer annular space. The barrier between the two air streams is a proprietary material that is able to transfer water molecules from the damper stream to the drier stream (the device is the mass transfer analog to a double pipe heat exchanger). The SRAT air purge was 0.715 SLM during these simulations. A nominal air flow of 4 SLM was selected for the annular purge.

The water peak eluted on the B column of the GC during the peak integration window of the Hi Fe-Lo Mn and Lo Fe-Lo Mn runs. The water peak was outside the integration window of the other two runs. The water peak area of the first run (Hi Fe-Lo Mn) was near the detection limit $(<200 \mu \mathrm{V} \cdot \mathrm{s})$ during the first eight hours of the SRAT. Room air had a peak area of about $4000 \mu \mathrm{V} \cdot \mathrm{s}$ for comparison. The purges were started early, and the dryer had reached steady state prior to starting to heat the SRAT up for acid addition. The ACTL air compressor failed, however, about eight hours into the first pair of SRAT runs. Since nitrite destruction was essentially complete, the dryer purges were shut off for the remainder of the first pair of runs.

Instead of using 4 SLM of compressed air to purge the dryers, a 1 SLM flow of compressed gas cylinder air was used during the second pair of runs (the flow reduction was made to conserve the available cylinder air). The dryer purge was not started until nitric acid addition was started. The chilled air moisture content was running about $2400 \mu \mathrm{V} \cdot \mathrm{s}$ in peak area at the time. The approach to steady state conditions is shown in Figure 9. 
SRNL-STI-2009-00606, REVISION 0

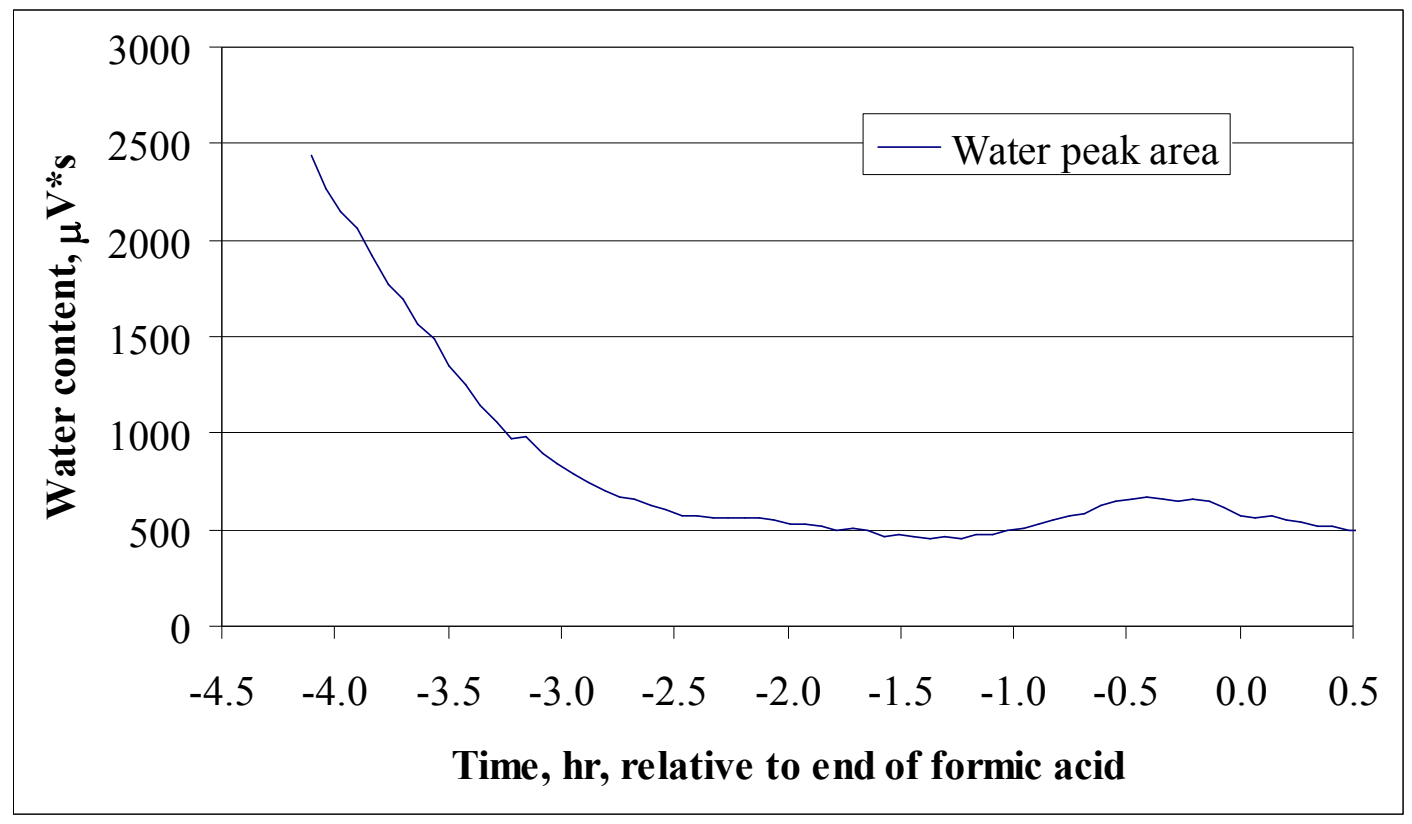

Figure 9. Performance of Nafion dryer during Lo Fe-Lo Mn test

The off-gas moisture content was significantly lower by the time that nitrite destruction became significant (about two hours before the end of formic acid). The slow approach to steady-state may indicate that the proprietary wall material is hydrophilic. Moisture adsorbed and stored in the tube wall must be partially removed in addition to the moisture in the off-gas before steady state conditions are reached. There should be a stable moisture concentration profile across the tube wall once steady state is reached.

About an $80 \%$ reduction in moisture content of the GC injection sample was achieved in the Lo Fe-Lo Mn test at a dryer purge/SRAT purge ratio of 1.4 to 1 . This reduced moisture content was maintained until the dryer purge was turned off. A $>91 \%$ reduction in moisture content was inferred for the earlier Hi Fe-Lo Mn test using a higher dryer purge/SRAT purge ratio of 5.6 to 1 and assuming an identical moisture content in the SRAT off-gas purge leaving the chilled condenser. The presence of the Nafion dryers in the SRAT off-gas system added about one-half inch of water column additional pressure drop to the system (the shortest available Nafion dryer unit was chosen to minimize additional pressure drop). 


\subsection{CONCLUSIONS}

A preliminary assessment of the processing characteristics and acid requirements of the four sludge matrix simulants was successfully completed. These parameters are needed to proceed forward with the additional planned tests in the sludge matrix study. The preliminary testing was exclusively with low noble metal concentrations and low total acid stoichiometry. The completed tests represent less than a quarter of the planned SRAT runs in the full sludge matrix study. Processed feed slurry was prepared for DWPF and Office of Environmental Management funded melt rate studies. The four completed SRAT runs provided data on composition and physical properties of the SRAT products. Updated values for formate loss and nitrite-to-nitrate conversion were found that can be used as inputs to the acid calculations for the remaining sludge matrix process simulations.

The four near minimum acid requirements for nitrite destruction were found at $105 \%$ of the Koopman minimum stoichiometric acid equation prediction. Data indicate that there was a small amount of excess acid in all four cases. The Lo Fe-Lo Mn simulant, however, was apparently further from minimum acid at $105 \%$ than the other three simulants. This could be due to analytical uncertainty rather than an issue with the Koopman minimum acid equation. This group of four tests extends the range of insoluble solids concentrations over which the new Koopman minimum stoichiometric acid equation has been validated.

The following additional preliminary observations were made:

- Hydrogen generation rate was not an issue in these tests. Hydrogen was only detected in the Lo Fe-Lo Mn run and only at very low concentrations $(<0.01 \mathrm{vol} \%)$.

- Mercury stripping was less efficient than expected at about $1000 \mathrm{~g}$ steam $/ \mathrm{g}$ mercury stripped. Only about $25 \%$ of the initial concentration of $1.5 \mathrm{wt} \% \mathrm{Hg}$ in the total solids was removed in 13-14 hours of boiling, when $70 \%$ needed to be removed to meet the DWPF SRAT product specification of $0.45 \mathrm{wt} \%$ in the total solids. Additional reflux time is recommended for future tests.

- Representative sampling of mercury in the SRAT was problematic from a material balance closure perspective. Sample results were reproducible across independent samples, but were unrealistically low in some cases. The results seem to indicate that $\mathrm{Hg}$ dispersion in the lab-scale SRAT vessel is the issue rather than sampling. Some visual observations during post-run rig disassembly tend to confirm some partial segregation of mercury from the bulk SRAT product slurry.

- Foaminess was not an issue using the nominal DWPF antifoam addition strategy in these tests.

- Ammonia was detected in the off-gas condensate samples but was not present in significant quantities.

- One of the SRAT products (an HM-type simulant) was much more viscous than the other three SRAT products even though it had the lowest $\mathrm{wt} \%$ insoluble solids. This finding is consistent with results from real sludge samples.

These observations demonstrate the potential for the full sludge matrix study to increase our understanding of the impact of compositional variations on DWPF processing behavior. 


\subsection{FUTURE WORK}

A set of tests appears to have essentially found the minimum acid stoichiometry for nitrite destruction in at least three of the four cases to within a few percent, which is typically the point of diminishing returns for experimental SRAT simulations. The Lo Fe-Lo Mn simulant may need to be retested at the low noble metal case to better define the minimum acid stoichiometry for it. A decision on whether or not to do this should be delayed until other sludge matrix study SRAT run data become available. The four low acid-low noble metal runs completed seem to have been adequately RedOx balanced, since the pre-run assumptions about formate loss and nitrite-to-nitrate conversion had small off-setting errors.

The next step should be to repeat these four runs using high noble metal concentrations and low total acid to see if noble metal concentration has a significant impact on the acid requirement for nitrite destruction and to obtain additional information on formate loss and nitrite-to-nitrate conversion for these four simulants. Past data have suggested that noble metals promote nitrite destruction reactions that consume more acid and also that less acid is needed to destroy nitrite (an apparent contradiction). The acid added to the Lo Fe-Lo Mn simulant can be decreased in this group relative to the other three simulants in order to gauge the necessity of repeating the Lo Fe-Lo Mn-Lo noble metal-Lo total acid run.

An evaluation should be performed at this point to determine if a suitable minimum acid requirement has been found for all eight simulant cases. One or two replicate trials might be needed to refine the behavior and/or results of some of the individual SRAT run cases. The next step would be to test the eight simulants again using high total acid. High total acid relative to low total acid would be a fixed quantity across the eight compositional cases. It would be an increment of extra acid per liter of simulant (potentially adjusted to offset small differences in total solids content) added to the minimum stoichiometric acid requirement. The impact of this excess acid on processing properties could then be evaluated as a function of the compositional changes in the eight simulants.

Two midpoint SRAT runs are needed to assess the non-linearity of the observed properties across the compositional matrix and to evaluate the variance of the results at an intermediate point. It would not be unusual for a preliminary statistical assessment at this point (18 SRAT runs) to show that one or two of the SRAT results appear to be outliers, and it might be necessary to replace the data from those tests with data from replacement SRAT tests before performing linear statistical modeling on the factors in the sludge matrix.

The expected outcome of the modeling would be to characterize the sensitivity of various processing quantities, such as hydrogen generation, rheology, foaminess, etc., to changes in the composition of the insoluble solids. This characterization would help in predicting the likely processing behavior of new sludge batches. 


\subsection{REFERENCES}

${ }^{1}$ Pickenheim, B. R., Improvement of DWPF SRAT Acid Equation, TTQAP: WSRC-RP-200700348, SRNL, Aiken, SC, 29808 (June 2007).

2 Koopman, D. C., Statistical Evaluation of Processing Data from the Rh-Ru-Hg Matrix Study, SRNL-STI-2009-00084, SRNL, Aiken, SC, 29808 (April 2009).

${ }^{3}$ Lambert, D. P., Sludge Preparation for Integrated Sludge Matrix Testing, SRNL-L31002009-00110, SRNL, Aiken, SC, 29808 (April 2009).

${ }^{4}$ Koopman, D. C., Preliminary Evaluations of Two Proposed Stoichiometric Acid Equations, SRNL-L3100-2009-00146, SRNL, Aiken, SC, 29808 (June 2009).

${ }^{5}$ Marek, J. C. and R. E. Eibling, Calculational Algorithms for Nitric Acid Sludge Adjustment, SRTC-PTD-92-0050, SRTC, Aiken, SC, 29808 (September 1992).

6 Jantzen, C. M. and M. E. Stone, Role of Manganese Reduction/Oxidation (RedOx) on Foaming and Melt Rate in High Level Waste Melters, WSRC-STI-2006-00066, Savannah River National Laboratory, Aiken, SC, 29808 (March 2007).

${ }^{7}$ Lambert, D. P., M. E. Stone, B. R. Pickenheim, D. R. Best, and D. C. Koopman, Sludge Batch 5 Simulant Flowsheet Studies, SRNS-STI-2008-00024, Savannah River National Laboratory, Aiken, SC, 29808 (October 2008).

${ }^{8}$ Lambert, D. P., B. R. Pickenheim, and D. R. Best, DWPF SB6 Initial Flowsheet Testing SB6-1 to SB6-6 4L Tests of SB6A and SB6B Simulants, SRNL-STI-2009-00413, Savannah River National Laboratory, Aiken, SC, 29808 (July 2009).

${ }^{9}$ Stone, M. E. and D. R. Best, Sludge Batch 4 Simulant Flowsheet Studies: Phase II Results, WSRC-STI-2006-00109, Savannah River National Laboratory, Aiken, SC, 29808 (December 2006).

${ }^{10}$ Koopman, D. C., D. P. Lambert, D. R. Best, M. J. Barnes, DWPF CPC Simulant Flowsheet Testing in Support of Sludge Batch 4 Qualification, WSRC-STI-2006-00062, Savannah River National Laboratory, Aiken, SC, 29808 (October 2006). 


\section{APPENDIX A. RHEOLOGY DATA}


Rheological data not included in Section 4.6 is included here. Data for the Hi Fe-Hi Mn, Lo Fe-Hi Mn, and Lo Fe-Lo Mn SRAT products are included in the three figures below. Up and down flow curves are shown for replicates one and two ( $\mathrm{r} 1$ and $\mathrm{r} 2$ ).

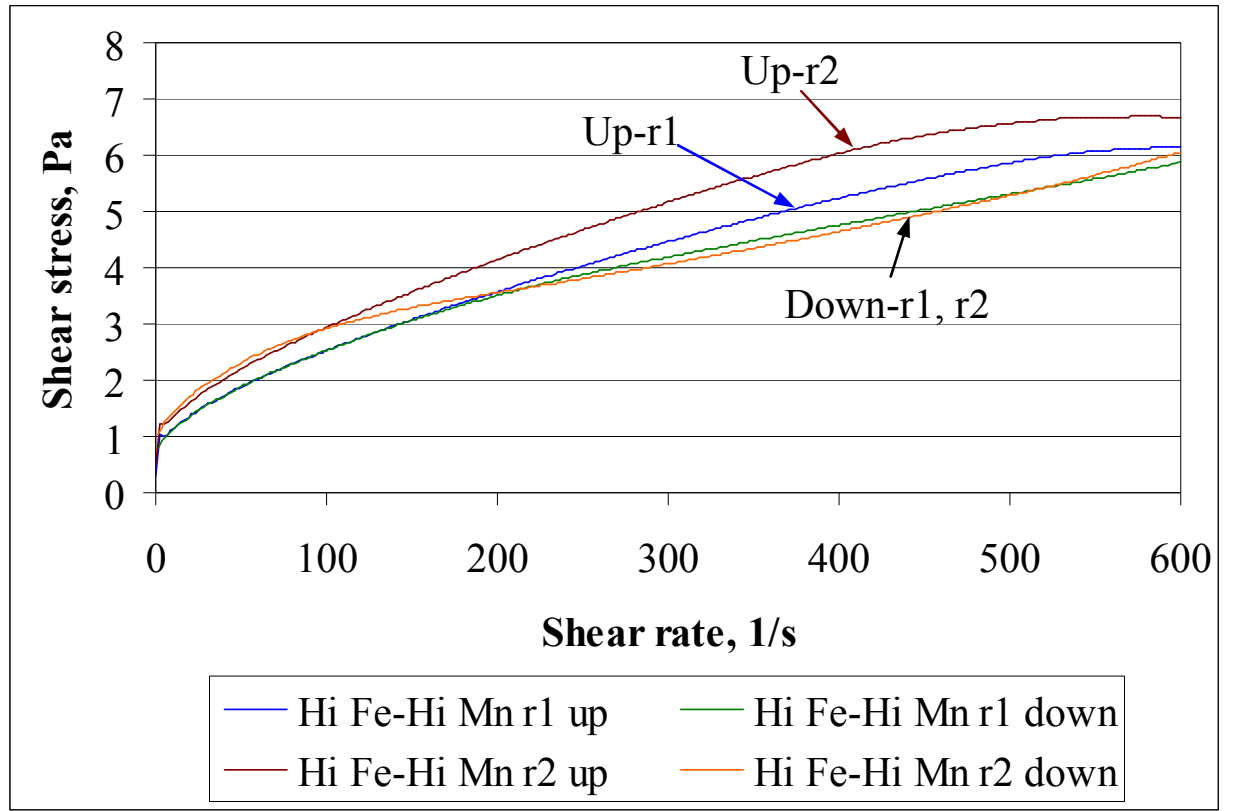

Figure A-1. Hi Fe-Hi Mn SRAT product flow curves.

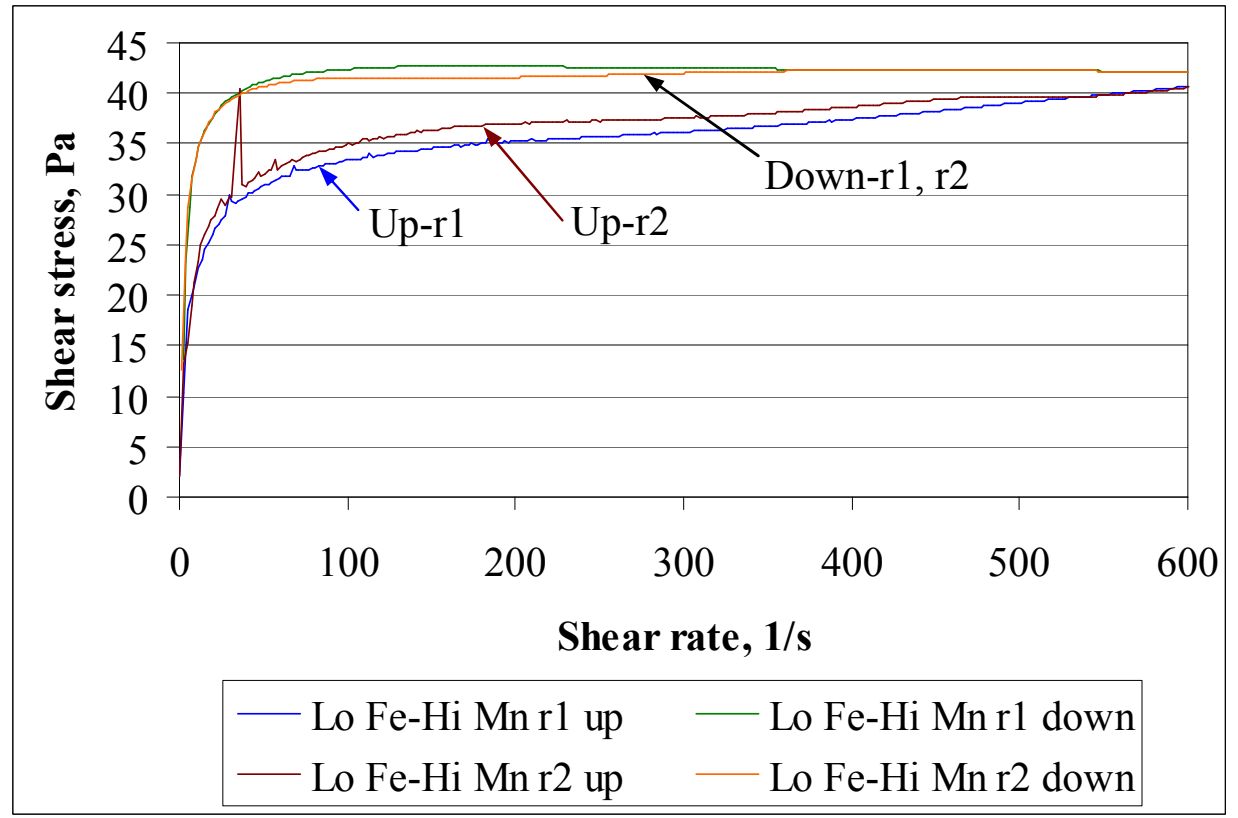

Figure A-2. Lo Fe-Hi Mn SRAT product flow curves. 
SRNL-STI-2009-00606, REVISION 0

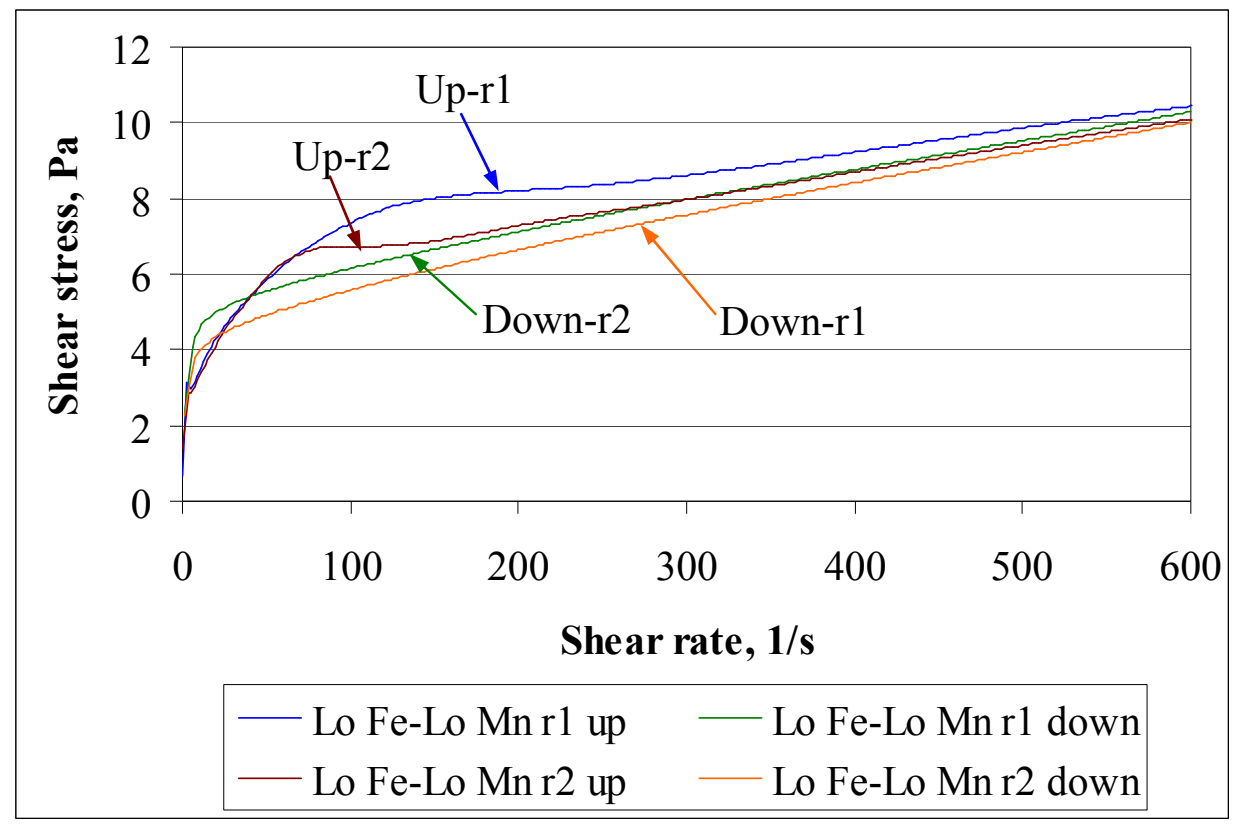

Figure A-3. Lo Fe-Lo Mn SRAT product flow curves. 


\section{Distribution:}

S. L. Marra, 773-A

A. B. Barnes, 999-W

D. A. Crowley, 773-43A

S. D. Fink, 773-A

C. W. Gardner, 773-A

B. J. Giddings, 786-5A

C. C. Herman, 999-W

F. M. Pennebaker, 773-42A

J. E. Occhipinti, 704-S

D. C. Sherburne, 704-S

R. T. McNew, 704-27S

J. F. Iaukea, 704-30S

J. W. Ray, 704-S

H. B. Shah, 766-H

J. M. Gillam, 766-H

B. A. Hamm, 766-H

D. D. Larsen, 766-H

M. E. Smith, 704-30S

C. J. Bannochie, 773-42A

D. K. Peeler, 999-W

N. E. Bibler, 773-A

M. E. Stone, 999-W

B. R. Pickenheim, 999-W

J. D. Newell, 999-W

A. I. Fernandez, 999-W

J. M. Pareizs, 773-A

S. H. Reboul, 773-A

D. H. Miller, 999-W

A. S. Choi, 999-W

J. M. Bricker, 704-27S

T. L. Fellinger, 704-26S

E. W. Holtzscheiter, 704-15S

M. T. Keefer, 766-H 